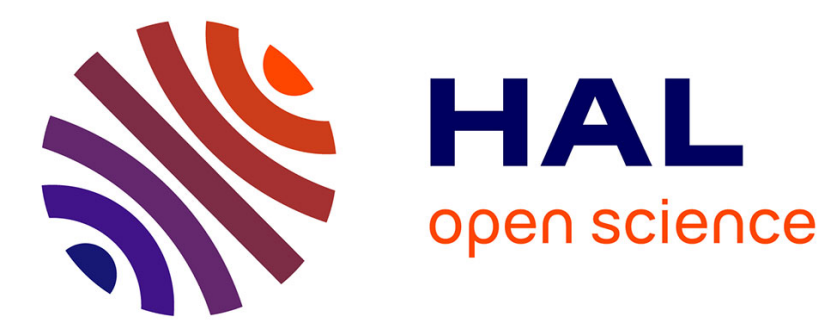

\title{
Distant but close in sight. Firm-level evidence on French-German productivity gaps in manufacturing
}

Thomas Grebel, Mauro Napoletano, Lionel Nesta

\section{To cite this version:}

Thomas Grebel, Mauro Napoletano, Lionel Nesta. Distant but close in sight. Firm-level evidence on French-German productivity gaps in manufacturing. 2021. hal-03374310

HAL Id: hal-03374310

https://hal-sciencespo.archives-ouvertes.fr/hal-03374310

Preprint submitted on 12 Oct 2021

HAL is a multi-disciplinary open access archive for the deposit and dissemination of scientific research documents, whether they are published or not. The documents may come from teaching and research institutions in France or abroad, or from public or private research centers.
L'archive ouverte pluridisciplinaire HAL, est destinée au dépôt et à la diffusion de documents scientifiques de niveau recherche, publiés ou non, émanant des établissements d'enseignement et de recherche français ou étrangers, des laboratoires publics ou privés. 


\section{SciencesPo}

DISTANT BUT CLOSE IN SIGHT. FIRM-LEVEL

EVIDENCE ON FRENCH-GERMAN PRODUCTIVITY GAPS IN MANUFACTURING

Thomas Grebel

Mauro Napoletano

Lionel Nesta

SCIENCES PO OFCE WORKING PAPER $n^{\circ}$ 03/2021 


\section{ofce}

\section{SciencesPo}

EDITORIAL BOARD

Chair: Xavier Ragot (Sciences Po, OFCE)

Members: Jérôme Creel (Sciences Po, OFCE), Eric Heyer (Sciences Po, OFCE), Sarah Guillou (Sciences Po, OFCE), Xavier Timbeau (Sciences Po, OFCE)

\section{CONTACT US}

OFCE

10 place de Catalogne | 75014 Paris | France

Tél. +33144185424

www.ofce.fr

This Working Paper:

Thomas Grebel, Mauro Napoletano and Lionel Nesta

Distant but close in sight. Firm-level evidence on French-German productivity gaps in manufacturing Sciences Po OFCE Working Paper, $\mathrm{n}^{\circ}$ 03/2021.

Downloaded from URL: www.ofce.sciences-po.fr/pdf/dtravail/WP2021-03.pdf

DOI - ISSN 
ABOUT THE AUTHORS

Thomas Grebel, Technische Universita"t IImenau

Email Address: Thomas.Grebel@tu-ilmenau.de

Mauro Napoletano, Université Côte d'Azur, CNRS, GREDEG and SKEMA Business School, Sciences Po-OFCE, Institute of Economics, Scuola Superiore di Studi Universitari e di Perfezionamento "Sant'Anna"

Email Address: mauro.napoletano@sciencespo.fr

Lionel Nesta, Universit'e Co^te d'Azur, CNRS, GREDEG and SKEMA Business School, Sciences Po-OFCE

Email Address: lionel.nesta@sciencespo.fr

\section{ABSTRACT}

We study the productivity level distributions of manufacturing firms in France and Germany, and how these distributions evolved across the Great Recession. We show the presence of a systematic productivity advantage of German firms over French ones in the decade 2003-2013, but the gap has narrowed down after the Great Recession. Convergence is explained by the better growth performance of French firms in the post-recession period, especially of those located in the top percentiles of the productivity distribution. We also highlight the role of sectoral growth, firm size and export intensity in explaining the above convergence. In contrast, the contribution of allocative efficiency was small.

\section{KEYWORDS}

International productivity gaps, productivity distributions, firm level comparisons

J EL

L10, N10, D24 



\title{
Distant but close in sight. Firm-level evidence on French-German productivity gaps in manufacturing
}

\author{
Thomas Grebel; Mauro Napoletano; Lionel Nesta
}

September 13, 2020

We study the productivity level distributions of manufacturing firms in France and Germany, and how these distributions evolved across the Great Recession. We show the presence of a systematic productivity advantage of German firms over French ones in the decade 2003-2013, but the gap has narrowed down after the Great Recession. Convergence is explained by the better growth performance of French firms in the post-recession period, especially of those located in the top percentiles of the productivity distribution. We also highlight the role of sectoral growth, firm size and export intensity in explaining the above convergence. In contrast, the contribution of allocative efficiency was small.

Keywords: International productivity gaps, productivity distributions, firm level comparisons.

JEL classification: L10, N10, D24

\footnotetext{
"Technische Universität Ilmenau (Germany).

†Université Côte d'Azur, CNRS, GREDEG and SKEMA Business School, (France), Sciences Po, OFCE (France), and Institute of Economics, Scuola Superiore di Studi Universitari e di Perfezionamento "Sant'Anna" (Italy).

'Université Côte d'Azur, CNRS, GREDEG and SKEMA Business School (France) and Sciences Po, OFCE, (France).
} 


\section{Introduction}

This work studies firm level productivity differences between France and Germany. Drawing on a unique census database of French and German firms, we build comparable productivity measures and we investigate the distributions of firm productivity levels in manufacturing. We also analyze how productivity distributions changed after the Great Recession, and we discuss how the latter affected the productivity gaps between France and Germany. In addition, we analyze the drivers of productivity gaps between the two countries by focusing in particular on factors like structural change, allocative efficiency, firm size and export intensity.

Cross-country studies of productivity have flourished in the last years, thanks to the increasing availability of firm level datasets. Empirical research employing such databases has opened new perspectives in productivity analysis that simply could not be obtained with aggregate statistics (see e.g. Bartelsman and Doms, 2000; Bartelsman et al., 2013; Force, 2014; Dosi et al., 2015; Syverson, 2011). It has also delivered fundamental insights about the key impact of firm heterogeneity and of market selection in determining aggregate productivity and differences in competitiveness among countries. A typical challenge when working with firm data is that a comparison across countries is quite difficult, because data collected by different countries comes with different definitions of variables, firms, not to mention different currencies. A further impediment is represented by confidentiality restrictions, which may affect the characteristics of the samples used in each country and thus undermine the representativeness of comparative analyses performed on them. To this, one must add that firm level productivity analyses are sensitive to the procedure used to estimate productivity, especially when total factor productivity metrics are concerned (Bartelsman and Wolf, 2018).

To circumvent these problems, recent contributions (Bartelsman et al., 2013, 2005; Force, 2014) have developed harmonized comparative analyses based on moments of the distributions of firm productivity as well as other firm characteristics. Such a "distributed micro-analysis" approach (DMD, see Bartelsman et al., 2004, 2018a) involves using common procedures and running common software at the different national statistical offices in order to retrieve the indicators and statistical moments or to conduct statistical analyses. In this way, a harmonized cross-country dataset containing indicators of underlying distributions of firm characteristics can be obtained without breaching confidentiality restrictions. In this paper we follow a similar approach, but we broaden the scope of the analysis with respect 
to previous studies, in that we do not just focus on single moments of the productivity distributions or on indicators capturing firm productivity variation within countries. We track instead the whole distribution of firm productivity levels by taking into account all distribution percentiles and by studying them cross-country and over time. In addition, we estimate total factor productivity by employing the non-parametric methodology developed in Good et al. (1996). Besides allowing one to estimate comparable TFP measures without pooling together firm-level data from different countries, this procedure has two additional advantages. First, it does not assume that different countries share the same production technology. Second, it is consistent with the methodologies employed to build comparable productivity measures at the industry level (e.g. the EU-KLEMS, see also Bellone et al., 2014, for more discussion).

We apply the above approach to compare the distributions of firm productivity levels in France and in Germany in the 2003-2013 decade. The choice of the countries to analyze was driven partly by data availability and partly by their economic importance. France and Germany are indeed the two most important economies of the European Union, accounting for nearly $42 \%$ of the total GDP of the area. In addition, their competitiveness performance has been opposite in the last decade. On the one hand, France has been characterized by a modest but persistent trade deficit (see also Martin et al., 2019). On the other hand, Germany has instead scored a sizeable trade surplus, ranking as the second top largest world net exporting country after China. As differences in trade performance are very much related to differences in firm productivity (see Bernard et al., 2007; Wagner, 2007), shedding light on the evolution of the distribution of firm productivity levels may contribute to explain the different trade performance of the two countries.

Furthermore, we study how the distributions of firm productivity levels and the aggregate productivity growth rate evolved through the Great Recession. Major economic crises can have important effects on productivity. For instance, recent accounts of long-term productivity trends in advanced countries (e.g. Bergeaud et al., 2016) show that many deep recessions constitute structural breaks in aggregate productivity dynamics. Besides, a good deal of research building on the seminal insight of Schumpeter (1942) has conjectured that recessions can increase productivity, by enhancing market reallocation toward more efficient firms and triggering the exit of inefficient ones (see e.g. Caballero and Hammour, 1994, 1996). This "cleansing effect" hypothesis has however received little support from an empirical perspective. Few empirical studies corroborate that recessions (see e.g. Foster et al., 2016; Bartelsman et al., 2019, for some recent contributions) boost reallocation. 
In addition, some works suggest that major recessions may on the contrary have severe hysteresis effects and depress potential output and productivity rather than increase them (see Ball, 2014; Fernald, 2015). Finally, downturns may trigger adjustment processes such as labor hoarding, which eventually leads to a reduction in labor productivity (see Biddle, 2014; Barth et al., 2017). Also, the heterogeneous ways countries' labor markets respond to adverse economic shocks can affect cross-country productivity differentials. (Bohachova et al., 2011; Aiginger et al., 2011). This is in particular important in the case of the France vs. Germany comparison. This is because the latter country has displayed much greater resilience to the Great Recession compared to France (as well as to other countries in the European Union), by quickly recovering the pre-crisis levels of GDP and employment.

After studying in depth productivity levels distributions, we also study some of the drivers underlying their shifts. We focus in particular on location shifts, and for this purpose we perform several decomposition exercises of the aggregate productivity growth rate that allow us to evaluate how productivity growth across the Great Recession has been impacted by factors like structural change and allocative efficiency. In addition, we evaluate the contributions to overall growth by firms with different sizes and export intensities. These are all factors that have received great attention in recent cross-country analyses of productivity growth (see e.g. Duarte and Restuccia, 2010; Bartelsman et al., 2013; Gopinath et al., 2017; Wagner, 2007).

Our results show that German manufacturing firms have outperformed French ones in terms of productivity levels in the 2003-2013 period. The gap was systematic across all percentiles of the productivity distribution, and it was there before the Great Recession. The gap has however narrowed down in the post-crisis period, and the productivity levels of French and German firms have converged. We show that convergence was due to the higher productivity growth of French firms, especially by most productive ones, i.e. those located in the top percentiles of the distributions. Moreover, we show that the magnitude of the gap display variation across the productivity metrics used, and it is, in particular, lower when using total factor productivity, a result which points to differentials in factor utilization across countries (especially in the post-recession period). Furthermore, the results of our decomposition analyses highlight the great contribution market shares reallocation in explaining sectoral productivity growth, and the contributions of medium-sized firms and of firms with medium export intensity to the productivity convergence between France and Germany. The same results downplay instead the role of allocative efficiency. Indeed, in line with recent works (Foster et al., 2016; Bartelsman et al., 2018b) we do not find evidence 
that the Great Recession boosted reallocation across firms. At the same time, several of the results we obtain point to the presence of important frictions in the market selection process during the post-recession phase and they highlight the impact the recession had on firms most exposed to trade. These also hint at the fact that the market selection is a multifaceted phenomenon that needs to be analyzed by taking several indicators into account.

The rest of the paper is structured as follows. In Section (2) we present our database including the harmonization required to make reliable comparisons. Section (3) describes the productivity measures and the methodology we employ in our analysis. In Section (4), we provide a first comparison on France's and Germany's distributions of firm productivity levels. In Section 5 we analyze those distributions before and after the Great Recession. Section 6 digs into the drivers of Franco-German differences in productivity by examining the role played by structural change, allocative efficiency, and the contributions of firms with different size and export intensity. Section 7 puts the different threads together and discusses the implications of the various results presented in light of the existing literature. Finally, Section 8 concludes.

\section{Data}

The data come from 4 main sources: (i) administrative fiscal files (FICUS and FARE) as supplied by the French statistical office (Insee-DGFiP), which contains comprehensive balance-sheet information for all firms operating in France; (ii) the AFiD (Amtliche Firmendaten für Deutschland) of the German Statistical Office (Destatis), which delivers cost, investment, and balance-sheet information of manufacturing firms with at least 20 employees; (iii) the Groningen EU KLEMS database, from which we use country-industry specific deflators; and (iv) the GGDC Productivity Level Database to adjust our data to purchasing power parity (PPP). Additionally, we retrieve information about the French corporate tax rates and average hours worked by industry from INSEE. For the German case, we take corporate tax rates published by Eurostat and the average hours worked per industry from Destatis. Regarding annual long-term interest rates, we also use Eurostat data for both countries.

In principle, the French administrative fiscal files (AFF in the following) and the German official firm database (AFiD) provide the same information, although in different qualities. Whereas the French data is comprehensive containing almost all conceivable balance sheet information, the German counterpart is a collection of representative samples. Thereof, 
we draw on the so-called "cost-structure survey (CCS)", which appears to be the most comprehensive survey on German firm-level data. A further caveat is that data protection laws do not allow retrieving information on German firms smaller than 20 employees. Consequently, we had to reduce the scope of our study to firms with 20 or more employees. Also, the way we could access the data was different in the two countries. On the French side, a remote but direct access was available. For Germany, due to confidentiality restrictions, we had to write a script (STATA 14), and send it to the statistical office, which then ran the script and sent the results back to us. Because of these restrictions, the datasets could not be merged. To circumvent this problem, we applied the methodology proposed by Bellone et al. (2014) (see also the next section). For this, we built a database containing productivity indicators for both countries at the percentile level on the 2-digit industry level (NACE Statistical Classification of Economic Activities in the European Community).

On average, the number of French firms identified by the French statistical office were 21,673 firms per year. We could retrieve the information we required for $91 \%$ of these firms, which amounts to 19,665 firms, on average. The German statistical office identified about $64 \%$ more firms in the manufacturing sector, i. e. 36,526 firms, on average. Due to the design of the German data collection process, the information of only $29 \%$ of firms is available on average. ${ }^{1}$

The sectoral comparisons we perform in our empirical study are based on the harmonized European classification system, i.e. the Statistical Classification of Economic Activities in the European Community (NACE rev. 2, 2008). The industries we selected all belong to manufacturing, which are classified in category $\mathrm{C}$ of the first level of the NACE rev. 2 (2008). With regard to the aggregation level, we use the 2-digit level comprising industry codes 10 to 33. A more fine-grained disaggregation is not feasible, as the correspondence between the French and the German version of the NACE rev. 2 (2008) classification, i. e. the Nomenclature d'Activité Française, rev 2 (NAF rev. 2, 2008) and the Klassifikation der Wirtschaftszweige, Ausgabe 2008 (WZ 2008), respectively, is not given. On the 2-digit level, however, the French and the German classification are congruent.

Table 1 shows the variables required for harmonization purposes across the two countries and for calculating productivity measures. The first variable in this table, $\mathrm{VA}_{i}$ indicates the

\footnotetext{
${ }^{1}$ The full list of industries is provided in Table A2 We drop some industries because of confidentiality issues. Further details are found in Table A2. The relevant set of comparable variables that we use in our analysis are reported in Table 1. The harmonization process is described below and the raw data, together with their correspondence in each data country source, are presented in Table A1 in the Appendix.
} 
Table 1: Variables and Definitions

\begin{tabular}{|c|c|}
\hline Variable & Harmonized Definition \\
\hline $\mathrm{VA}_{i}$ & $\begin{array}{l}\text { real value added: total sales minus trading goods minus raw materials minus } \\
\text { other costs, deflated using value added deflator from EU KLEMS }\end{array}$ \\
\hline $\mathrm{H}_{i}$ & average hours worked, calculated on the firm level \\
\hline $\mathrm{K}_{i}$ & firm real capital stock \\
\hline$\delta_{s}$ & $\begin{array}{l}\text { Defined as the ratio of average consumption of capital and average capital } \\
\text { stocks. }\end{array}$ \\
\hline $\mathrm{LE}_{s}$ & Life expectancy of capital is computed as the inverse of $(\delta)_{s}$. \\
\hline $\mathrm{M}_{i}$ & $\begin{array}{l}\text { Expenses in goods }+ \text { expenses in raw materials }+ \text { other expenses and } \\
\text { external charges. Deflated using intermediate inputs output deflator from EU } \\
\text { KLEMS. }\end{array}$ \\
\hline $\mathrm{Y}_{i}$ & Total sales deflated using output deflator from EU KLEMS. \\
\hline
\end{tabular}

Note: $i$ is the firm identifier.

real value added by firm $i$. Its precise calculation can be found in Table A1 in the Appendix. To make sure that country variables correspond, we checked the correspondence of every account that entered the variable $\mathrm{VA}_{i}$ in the balance sheets of firms of both countries. A somewhat greater challenge is to identify a variable for firm capital stock, required to calculate TFP. In vain, we searched for information on capital stock in German databases, whereas the French data readily contains capital stock information. As a consequence, we had to reconstruct a proxy for capital stock. The most widespread technique to do so is the so-called perpetual inventory method (PIM), which simply accumulates past investment while applying a certain rate of depreciation to past investment. As Mueller (2008) discusses, there are pros and cons to this method. For a short time series, as we have, many time slices will be lost when calculating the initial capital stock. At the same time, other procedures which use investment as a proxy for capital can produce poor approximations as well, because of the high volatility of investment. To reconcile at least some of these shortcomings, we decided in favor of a modified perpetual inventory method suggested by Mueller (2008) and Wagner (2010). They use the amount of depreciation and the average life expectancy $\overline{L E}_{s}$ by type of capital $s$ to calculate capital stock. With the respective information provided by the German statistical office (Destatis), a proxy for the initial value of firm capital stock $K_{i}$ is calculated by $K_{i}=\delta_{i} \times \overline{L E}_{s}$. To compute average life expectancy, we use the total capital stock (repurchasing value) at the 2-digit level and divide 
it by the amount of depreciation at current prices. Multiplying firm-level depreciation with the average life expectancy of respective capital types yields the initial firm capital stock. A caveat of this procedure is the underlying assumption about the industry-specific capital structure. This assumes that firms within an industry would apply the same depreciation routines. As we aggregate to the 2-digit industry level, this assumption seems feasible. For consistency reasons, we apply the same methodology for the German as well as for the French case. The remaining variables in Table (1), i. e. material input $\left(M_{i}\right)$ and production output $\left(Y_{i}\right)$, we could directly retrieve from firms' balance sheets.

All variables are converted to real values using the corresponding country-time-industry specific price deflators. To maintain consistency across countries, we use deflators from the same source, which is, the database supplied by the Groning EU KLEMS project. ${ }^{2} \mathrm{~A}$ last correction to be taken is the adjustment for purchasing power parity (PPP). Thus we take into account the fact that one euro of investment or wage buys different amounts of (capital) goods in the two countries. The PPP information from the GGDC Productivity Level Database serves as data source. ${ }^{3}$

\section{Productivity Measures and Methodology}

We use two traditional firm level productivity measures in our study. The first one is the standard apparent labor productivity (ALP) or value added per hour (VAH). The second one is total factor productivity (TFP), which takes the contributions of other production factors such as capital and material into account.

The calculation of labor productivity is straightforward: value added, in real terms, divided by the number of hours worked. Hence, labor productivity reads as:

$$
\mathrm{VAH}_{i}=\mathrm{VA}_{i} / \mathrm{H}_{i}
$$

For the estimation of total factor productivity (TFP), we follow the methodology applied by (Bellone et al., 2014). It consists of a non-parametric estimation technique using the Multilateral Productivity Index developed by Caves et al. (1982) extended by Good et al. (1996). It is an index number approach returning a transitive productivity index across countries. More precisely, the calculation of the TFP index is as in the following:

\footnotetext{
${ }^{2}$ See Jäger (2016) for details about these deflators.

${ }^{3}$ The GGDC Productivity Level Database (see Inklaar et al. (2009) for details) delivers PPP meassured in US dollars. Hence, we converted the French data into German PPP.
} 


$$
\begin{aligned}
\ln \mathrm{TFP}_{i t}^{F R}-\ln \mathrm{TFP}_{r t}^{D E} \cong & \left(\ln Y_{i t}^{F R}-\overline{\ln Y_{r t}^{D E}}\right)+\sum_{\tau=1}^{t}\left(\overline{\ln Y_{r \tau}^{D E}}-\overline{\ln Y_{\tau-1}^{D E}}\right) \\
& -\frac{1}{2} \sum_{j \in\{K, L, M\}}\left(S_{i j t}^{F R}+\overline{S_{r j t}^{D E}}\right)\left(\ln X_{i j t}^{F R}-\overline{\ln X_{r j t}^{D E}}\right) \\
& +\frac{1}{2} \sum_{\tau=1}^{t} \sum_{j \in\{K, L, M\}}\left(\overline{S_{r j t}^{D E}}+\overline{S_{r j \tau-1}^{D E}}\right)\left(\overline{\ln X_{r j t}^{D E}}-\overline{\ln X_{r j \tau-1}^{D E}}\right)
\end{aligned}
$$

The above formula defines a chain index that measures the change of TFP of a French firm $i$ from the German reference firm $r$, at time $t$. This change is congruent ${ }^{4}$ to the term on the right hand side, which consists of four components; the first, which denotes the percentage deviation of the output of the French firm $i$ from the output of the German reference firm $r$ in time $t$, the second, which adds up the annual changes in output of the German reference firm, the third, reflecting the weighted average of the relative input shares of production factors $\mathrm{K}$ (capital), L (labor), and M (material) compared to the German reference firm, and the fourth sub term, which accumulates the weighted average of production factor input ratios in comparison to the reference firm. Notice that we calculated reference firms for each industry. The industry identifier is neglected in the above TFP-index equation. Thence, $\mathrm{Y}_{i t}$ stands for real gross output of firm $i$ at time $t, X$ for the number of units in input of production factors $j$ with $j \in\{\mathrm{K}, \mathrm{L}, \mathrm{M}\}$; S denotes the share of input $\mathrm{X}$ in total output. The variables with an upper bar indicate the corresponding values of the reference firm, which are computed as the geometric mean of the corresponding firm level variables over all firms in year $t$. Subscripts $\tau$ and $j$ are indices for time and inputs, respectively. This methodology is particularly suited to comparisons within firm-level panel data sets as it guarantees the transitivity of any comparison between two firm-year observations by expressing each firm's input and output as deviations from a single reference point for each year. This transitivity property was especially suitable for our study as it allowed us to compare productivity levels across countries even in the impossibility of merging French and the German firm-level data due to confidentiality restrictions. In addition, compared to other methods, the above index approach does not rely on the

\footnotetext{
${ }^{4}$ The index is built on a second-order Taylor series, that reflects an approximation of the true change.
} 
estimation of an underlying production function.

The main object of our study is to track distributions of productivity levels across manufacturing firms in Germany and France over the period 2003-2013 by using VAH or TFP, as defined above. In particular, we focus on the effects caused by the Great Recession in 2008 on productivity in the two countries. So, we compare productivity distributions calculated in the two sub-periods 2003-2007 and 2009-2013. To give the most detailed picture possible, constrained by the technical condition of not being able to merge the data, we perform the cross-country comparisons at the 2-digit industry level.

The above cross-country and cross-periods comparative analysis of firm productivity levels distributions would clearly be simple if the firm data of both countries were contained in a single database. Because of the restrictions, as pointed out, this is impossible. Aside from the fact that we cannot have access to all firms, but only to firms with at least 20 employees, the analysis is biased, not containing the smallest firms of both economies. This amounts to a loss of more than $70 \%$ of firms. Nor is it possible to pinpoint single firms above the 20-employee threshold to apply a matching procedure. Any statistic computed on subgroups of firms with three or less firms would not be reported to us by the statistical office. This includes, industries with high concentration levels which were restricted for any type of investigation. In the end, we were left with the remaining industries depicted in Table (2). These figures report the minimum, the maximum, and the average number of observations by country and firm that entered our analysis. An immediate revelation is a high volatility in the available data across industries.

Instead of processing the data of single firms, futile because of confidentiality restrictions, we extract the distributions by industry and year from both databases, the French and the German one. We collect means and standard deviations by percentile and industry. Consequently, dividing the numbers in Table (2) by one hundred yields the number of observations, i.e. firms, by percentile. To simplify our analysis, we henceforth consider the mean of, for example, value added by hour worked (VAH) in a given percentile as if it were a firm. By doing so, we average out idiosyncratic firm differences within a percentile, while keeping the heterogeneity over the whole distribution by industry. We then have a unique balanced panel data set of 13 industries $\times 11$ years $\times 100$ percentiles for both France and Germany, yielding 28,600 observations, i.e. 14,300 observations for each country. ${ }^{5}$

\footnotetext{
${ }^{5}$ The advantage of this procedure is that it allows direct comparisons of productivity distributions across the two countries while conforming to data confidentiality issues. The caveat is that such data reduction rules out the possibility to analyze the role played by industry churning, i.e. firm entry into and exit from markets, in
} 
Table 2: Number of Observations by industry

\begin{tabular}{|c|c|c|c|c|c|c|c|}
\hline \multirow[b]{2}{*}{ ISIC } & \multirow[b]{2}{*}{ Sector Name } & \multicolumn{3}{|c|}{ France } & \multicolumn{3}{|c|}{ Germany } \\
\hline & & Min & Max & Avg & Min & Max & Avg \\
\hline 10 & Food products & 2811 & 3007 & 2911 & 985 & 1533 & 1341 \\
\hline 13 & Textiles & 490 & 916 & 686 & 60 & 478 & 262 \\
\hline 17 & Paper and paper products & 497 & 750 & 600 & 234 & 408 & 347 \\
\hline 20 & Chemicals and chemical products & 737 & 908 & 819 & 510 & 687 & 622 \\
\hline 22 & Rubber and plastic products & 1211 & 1492 & 1340 & 595 & 851 & 716 \\
\hline 23 & Other non-metallic mineral products & 714 & 842 & 785 & 427 & 779 & 595 \\
\hline 24 & Basic metals & 341 & 399 & 370 & 401 & 522 & 493 \\
\hline 25 & Fabricated metal products & 3374 & 3752 & 3562 & 1059 & 1632 & 1438 \\
\hline 26 & Computer, electronic and optical products & 580 & 834 & 687 & 425 & 594 & 522 \\
\hline 27 & Electrical equipment & 509 & 598 & 556 & 542 & 756 & 677 \\
\hline 28 & Machinery and equipment n.e.c. & 1322 & 1855 & 1551 & 1467 & 2074 & 1764 \\
\hline 29 & Motor vehicles, trailers & 426 & 559 & 487 & 456 & 665 & 541 \\
\hline 31 & Furniture & 399 & 596 & 514 & 60 & 439 & 242 \\
\hline 32 & Other manufacturing & 438 & 534 & 492 & 225 & 487 & 391 \\
\hline 33 & Repair and installation & 1289 & 1990 & 1594 & 273 & 541 & 426 \\
\hline
\end{tabular}

The resulting empirical distributions shall be analyzed in the following. We evaluate quantitatively distributional differences by carrying out parametric and non-parametric tests (see Sheskin, 2003). In particular, we use a standard t-test of differences in means assuming normality of the underlying distributions, in a first step. Second, we employ the Fligner-Policello test that focuses on the statistical difference between the medians. The advantage of this test opposite to the student t-test is that the Fligner-Policello test does not make any assumption about the underlying data generating process. In addition, it neither requires the shape of two distributions to stem from the same family of distributions, nor to have equal variances. Third, we perform the two-sample Kolmogorov-Smirnov test, which bears the merit to take the differences in percentiles into account.

\section{A first look at the distributions of firm productivity levels}

We begin with focusing on pooled productivity distributions of France and Germany over the entire sample period 2003-2013 and for all manufacturing frims. Figure (1) compares the empirical density functions in terms of VAH in the two countries. The solid black curve, explaining productivity growth. 
depicts the French density, the dashed line the German.

Figure 1: Probability density of French and German (VAH)

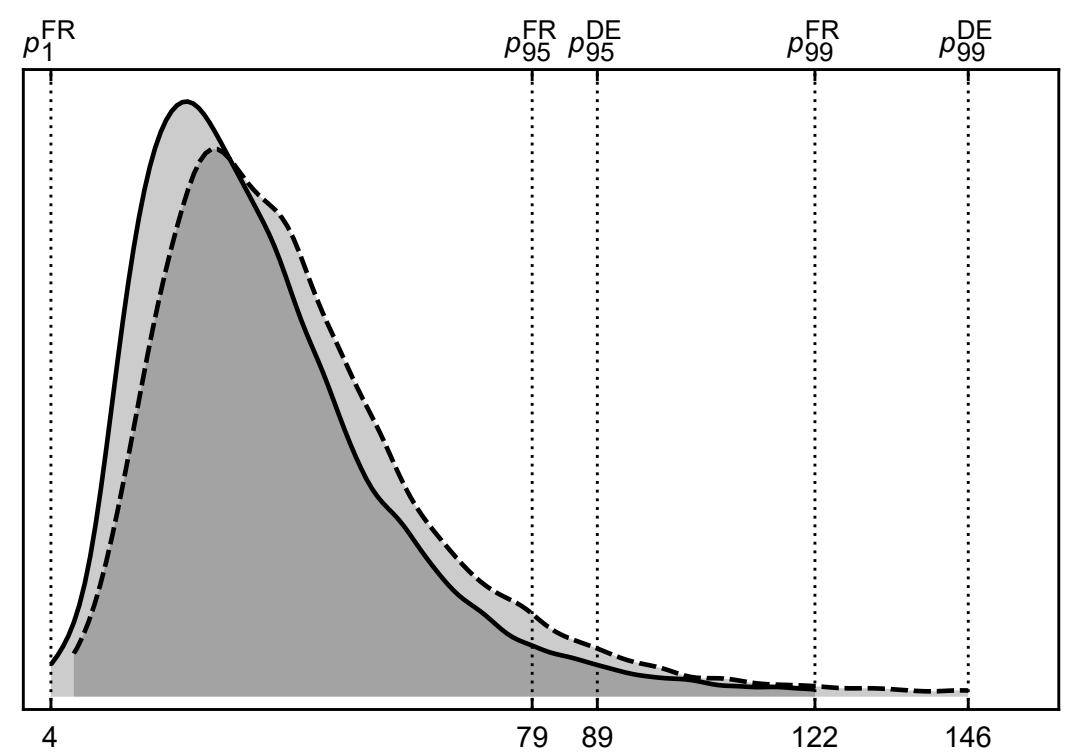

Figure 2: Probability density of French and German (TFP)

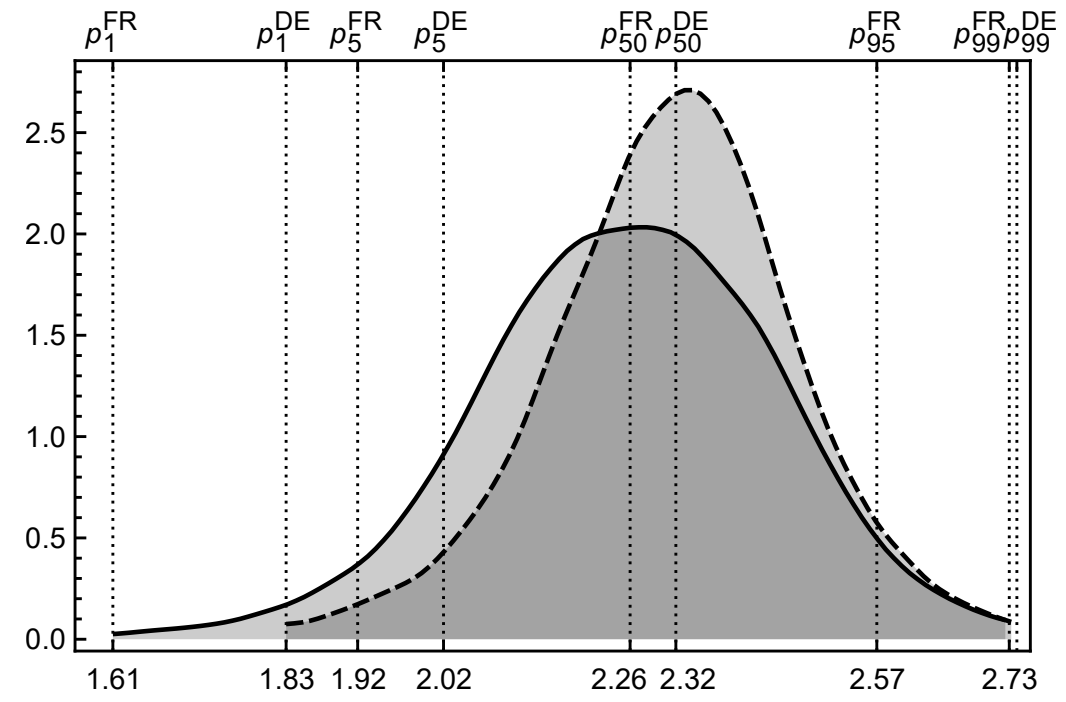

The analysis of both figures clearly indicates that all empirical distributions in our sample 
Table 3: Percentiles of productivity distributions and their differences

\begin{tabular}{|c|c|c|c|c|c|c|}
\hline \multirow[t]{2}{*}{ Statistic } & \multicolumn{3}{|c|}{ VAH } & \multicolumn{3}{|c|}{ TFP } \\
\hline & France & Germany & $€ \Delta$ in $\mathrm{VAH}$ & France & Germany & $\Delta$ in TFP \\
\hline$p_{1}$ & 4.3 & 7.8 & -3.5 & 1.609 & 1.826 & -0.217 \\
\hline$p_{5}$ & 12.9 & 15.7 & -2.9 & 1.916 & 2.024 & -0.107 \\
\hline$p_{10}$ & 16.3 & 19.7 & -3.4 & 2.006 & 2.103 & -0.097 \\
\hline$p_{50}$ & 33.2 & 38.4 & -5.2 & 2.258 & 2.315 & -0.057 \\
\hline$p_{90}$ & 64.3 & 72.9 & -8.6 & 2.497 & 2.51 & -0.014 \\
\hline$p_{95}$ & 78.6 & 88.7 & -10.1 & 2.567 & 2.578 & -0.011 \\
\hline$p_{99}$ & 122.3 & 146.0 & -23.7 & 2.733 & 2.743 & -0.010 \\
\hline$\mu$ & 38.2 & 43.8 & -5.6 & 2.247 & 2.309 & -0.063 \\
\hline$\sigma$ & 26.7 & 29.7 & -3.1 & 0.238 & 0.176 & 0.063 \\
\hline$\gamma$ & 75.4 & 161.1 & -85.7 & 20.433 & 5.896 & 14.537 \\
\hline$\omega$ & 5.3 & 3.3 & 2.0 & -2.256 & -0.303 & -1.953 \\
\hline
\end{tabular}

$p_{x}: x^{\text {th }}$ percentile; $\mu$ : mean; $\sigma:$ standard deviation; $\gamma:$ skewness; $\omega:$ kurtosis.

are far from a normal distribution, ${ }^{6}$ a result which is line with the robust empirical evidence about productivity distributions in other countries, and highlighted by a number of recent empirical studies (see e.g. Dosi et al., 2012, 2015; Force, 2014; Yu et al., 2017). Second, the figures indicate a productivity advantage of Germany over France. The distribution of productivity levels of German firms is considerably more shifted to the right than the one of French firms, either by considering VAH or TFP.

Table 3 sheds more light on these firm productivity differences by reporting specific percentiles $p_{c}$ of the French and German productivity distributions where $c \in\{1,5,10,50,95,99\}$. Notice that, as we converted all variables to Euro in German PPP, the difference between the French and Germany VAH can be interpreted literally. TFP is instead measured as a chain index in logarithms. Accordingly, differences must be interpreted as percentage points.

The table reveals that the productivity advantage of German firms over French ones emerges at any percentile considered. For instance, the first percentile of VAH for France $\left(p_{1}^{F R}\right.$ ) ends with about $€ 4$ value added per hour worked, the German with round $€ 8$. A difference of more than $€ 3$. The difference in favor of German firms almost doubles, when we look at the median $\left(p_{50}\right)$. For France, value added per hour of the median French firms is

\footnotetext{
${ }^{6}$ In addition, the analysis of undisplayed quantile-quantile plots indicates that both distributions display fat-tails (more pronounced for VAH than for TFP), another property detected by previous empirical studies.
} 
$€ 5$ lower than in the German case. The gap becomes dramatically large when we consider the most productive firms. The VAH advantage of German firms jumps from $€ 10.1$ to $€ 23.7$ when we move from the 95th to the 99th percentile.

The above differences in value added per hour do not account for differences in the rates of factors utilization across countries. The use of TFP allows one to control for these differences. To this, Table (3) reveals that the productivity lead of German firms is confirmed, though to a lower degree, with TFP. At the same time, the gap declines the higher the percentile in TFP. For instance, at the 1st percentile $\left(p_{1}\right)$ German firms are 22 percentage points more productive than French ones. The difference shrinks to 6 percentage points at the median $\left(p_{50}\right)$ declining to only 1 percentage point at the 99 th percentiles. This clearly points to high rates of factor utilization of German firms located in the right tail of the productivity distribution.

Furthemore, we perform with parametric and non-parametric tests of differences in distributions to check whether the above-described divergence in productivity levels are statistically significant. Additionally, we investigate whether productivity asymmetries between French and German firms emerge also when grouping firms by sectors of activity. Table 4 and 5 show the mean of productivity levels in France and in Germany (first and second column), their difference, as well as the values of respectively the Student-t test on difference in means, of the Fligner-Policello test of differences in medians and, finally, of the two-sample Kolmogorov test of differences in distributions. The statistics are reported for all manufacturing firms at the 2-digit industry level. The test results for labour productivity (Table 4) indicate that the advantage of German firms is statistically significant at the 5\% level, when considering manufacturing firms altogether. The null hypothesis that the two samples come from the same distribution is rejected both by the tests of differences in the mean and in the median (respectively the Student-t test and the Fligner-Policello test) and when considering the entire distribution (Kolmogorov-Smirnov test). In addition, the statistical significance of differences holds irrespectively of the way we calculate productivity (compare both tables, 4 and 5).

Finally, with few exceptions, the productivity advantage of German firms is systematic across all 2-digit industries in manufacturing. The exceptions, where France takes a significant lead, are, for instance, the "Chemicals and chemical products (20)" or "Rubber and plastic products (22)" industry. There, the French productivity advantage in VAH amounts to $€ 7.46$ or even $€ 12.73$, respectively. It seems interesting that the TFP gap takes opposite signs: in "Chemicals and chemical products (20)" the gap is slightly negative with 
$-0.9 \%$, in 'Rubber and plastic products (22)' it is positive with $13.8 \%$.

To sum up, there was a statistically significant productivity advantage of German firms over French firms in the 2003-2013 decade. This advantage was not affected by the way one computes productivity (value added or total factor productivity). In addition, it was detected both when pooling together all manufacturing firms as well as by grouping them at the 2-digit sectoral level.

Table 4: Productivity Differentials (by industry, 2003-2013) — VAH

\begin{tabular}{|c|c|c|c|c|c|c|c|}
\hline ISIC & Sector Name & $\mu_{F R}$ & $\mu_{D E}$ & $\Delta_{\mu}$ & Stud. $t$ & $\mathrm{KS} D$ & FP $U$ \\
\hline & & \multicolumn{6}{|c|}{ Labour Productivity } \\
\hline $10-33$ & All Manufacturing & 38.23 & 43.83 & -5.60 & 17.146 & 0.116 & 24.230 \\
\hline 10 & Food products & 23.52 & 39.13 & -15.61 & 13.447 & 0.316 & 17.871 \\
\hline 17 & Paper and paper prod. & 27.63 & 38.62 & -10.98 & 13.753 & 0.329 & 12.728 \\
\hline 20 & Chemicals and chem. prod. & 69.50 & 62.05 & 7.46 & -3.988 & 0.125 & -4.736 \\
\hline 22 & Rubber and plastic prod. & 50.16 & 37.44 & 12.73 & -16.765 & 0.350 & -20.603 \\
\hline 23 & Other non-metallic min. prod. & 33.78 & 42.97 & -9.19 & 9.608 & 0.194 & 10.965 \\
\hline 24 & Basic Metals & 42.21 & 50.80 & -8.59 & 5.911 & 0.264 & 12.475 \\
\hline 25 & Fabricated metal products & 35.14 & 39.54 & -4.40 & 6.888 & 0.160 & 6.180 \\
\hline 26 & Computer, electr. and opt. prod. & 39.55 & 46.52 & -6.97 & 5.825 & 0.140 & 6.800 \\
\hline 27 & Electrical equipment & 37.87 & 40.52 & -2.65 & 2.188 & $0.048 \dagger$ & 2.112 \\
\hline 28 & Machinery and equipment n.e.c. & 52.46 & 48.09 & 4.37 & -4.452 & 0.108 & -5.027 \\
\hline 29 & Motor vehicl., trail. and semi-trail. & 38.48 & 43.18 & -4.71 & 3.241 & 0.139 & 4.546 \\
\hline 32 & Other Manufacturing & 27.97 & 39.97 & -11.00 & 12.667 & 0.289 & 14.952 \\
\hline 33 & Repair and installation & 44.65 & 40.81 & 3.85 & -3.384 & 0.233 & -8.330 \\
\hline
\end{tabular}

Productivity differentials are computed as the difference between the average of French manufacturing firms $\left(\mu_{F R}\right)$ and the average of German manufacturing firms $\left(\mu_{D E}\right)$. Positive (negative) values indicate a productivity advantage in favour of France (Germany). Stud. $t$ stands for Student $t$ statistics for equality of means. KS $D$ stands for the absolute value of the maximum distance between the French and German cumulative distribution derived. Significance is derived from the Kolmogorov-Smirnov Test for stochastic dominance assuming normality in the productivity distribution. PF $U$ test stands for the Two-Sample Fligner-Policello Robust Rank Order Test. Symbol $\dagger$ indicates non-significance at 5 percent level.

\section{Productivity differences across the Great Recession}

Let us now study how the Great Recession has affected the Franco-German productivity gap we unveiled in the previous section. For this purpose, we repeat the comparative analysis of the distributions of firm productivity levels by splitting our sample in two sub-periods: a "pre-recession" period including observations relative to the years from 2003 to 2007 
Table 5: Productivity Differentials (by industry, 2003-2013) — TFP

\begin{tabular}{|c|c|c|c|c|c|c|c|}
\hline ISIC & Sector Name & $\mu_{F R}$ & $\mu_{D E}$ & $\Delta_{\mu}$ & Stud. $t$ & KS $D$ & FP $U$ \\
\hline & & \multicolumn{6}{|c|}{ Total Factor Productivity } \\
\hline $10-33$ & All Manufacturing & 2.247 & 2.309 & -0.063 & 25.381 & 0.158 & 26.750 \\
\hline 10 & Food Products & 2.122 & 2.245 & -0.124 & 16.046 & 0.345 & 18.145 \\
\hline 17 & Paper and paper prod. & 2.104 & 2.245 & -0.140 & 15.147 & 0.483 & 20.493 \\
\hline 20 & Chemicals and chem. prod. & 2.360 & 2.368 & -0.009 & $1.009 \dagger$ & $0.025 \dagger$ & -0.043 \\
\hline 22 & Rubber and plastic prod. & 2.410 & 2.272 & 0.138 & -21.327 & 0.456 & -28.997 \\
\hline 23 & Other non-metallic min. prod. & 2.164 & 2.274 & -0.109 & 14.003 & 0.291 & 16.404 \\
\hline 24 & Basic Metals & 2.252 & 2.345 & -0.093 & 12.461 & 0.290 & 15.698 \\
\hline 25 & Fabricated metal products & 2.273 & 2.303 & -0.031 & 4.236 & 0.086 & 3.950 \\
\hline 26 & Computer, electr. and opt. prod. & 2.265 & 2.346 & -0.081 & 7.244 & 0.135 & 7.474 \\
\hline 27 & Electrical equipment & 2.272 & 2.311 & -0.039 & 4.392 & 0.065 & 3.491 \\
\hline 28 & Machinery and equipment n.e.c. & 2.404 & 2.375 & 0.029 & -3.825 & 0.110 & -5.664 \\
\hline 29 & Motor vehicl., trail. and semi-trail. & 2.269 & 2.325 & -0.056 & 6.906 & 0.161 & 7.610 \\
\hline 32 & Other Manufacturing & 2.163 & 2.278 & -0.116 & 10.840 & 0.263 & 12.456 \\
\hline 33 & Repair and installation & 2.393 & 2.343 & 0.050 & -5.045 & 0.199 & -7.940 \\
\hline
\end{tabular}

Productivity differentials are computed as the difference between the average of French manufacturing firms $\left(\mu_{F R}\right)$ and the average of German manufacturing firms $\left(\mu_{D E}\right)$. Positive (negative) values indicate a productivity advantage in favour of France (Germany). Stud. $t$ stands for Student $t$ statistics for equality of means. KS $D$ stands for the absolute value of the maximum distance between the French and German cumulative distribution derived. Significance is derived from the Kolmogorov-Smirnov Test for stochastic dominance assuming normality in the productivity distribution. PF $U$ test stands for the Two-Sample Fligner-Policello Robust Rank Order Test. Symbol $\dagger$ indicates non-significance at 5 percent level.

and a "post-recession" phase relating to the interval 2009-2013. Figure 3 juxtaposes two panels with the distributional differences between France and Germany for the foregoing two periods. Instead of plotting the two probability density functions (PDFs) for France and Germany, we plot the difference between the two PDFs, i.e. $\mathrm{PDF}_{F R}-\mathrm{PDF}_{D E}$ (indicated by the black line in the figure), together with the percentiles of the respective country's density in each period. Moreover, to facilitate interpretation, we add a bar chart indicating the surplus (positive bars) or deficit (negative bars) of French firms in a given productivity class compared to Germany.

The left panels of Figure 3 reveals that the productivity advantage of German was already present before the Great Recession. In the first period of analysis, 2003-2007, the median value added per hour worked (VAH) was $€ 36.6$ in Germany and $€ 30.0$ in France a difference of more than $€ 6$ (compare also statistics in Table 6). Hence, a German worker, at a median firm, was about $20 \%$ more productive than his/her French counterpart. The stochastic dominance of German firms prevails also in higher percentiles, although in a 
Figure 3: Difference in VAH distribution - France vs. Germany

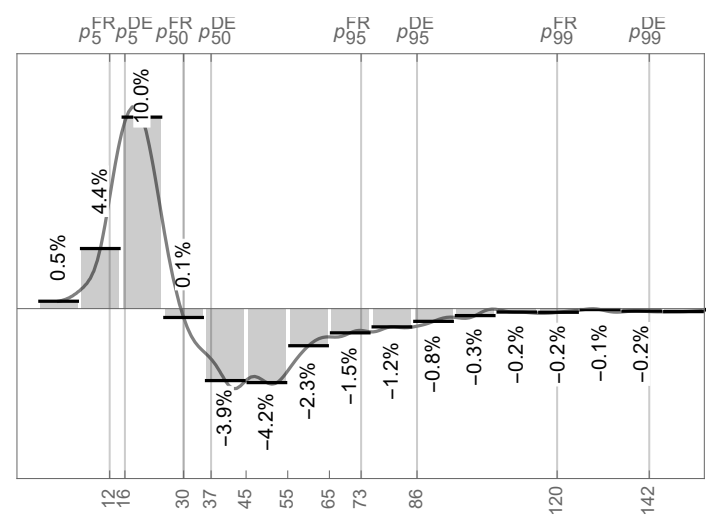

Apparent Labor Productivty (VAH)

(a) Difference in probability density France vs. Germany (2003-2013)

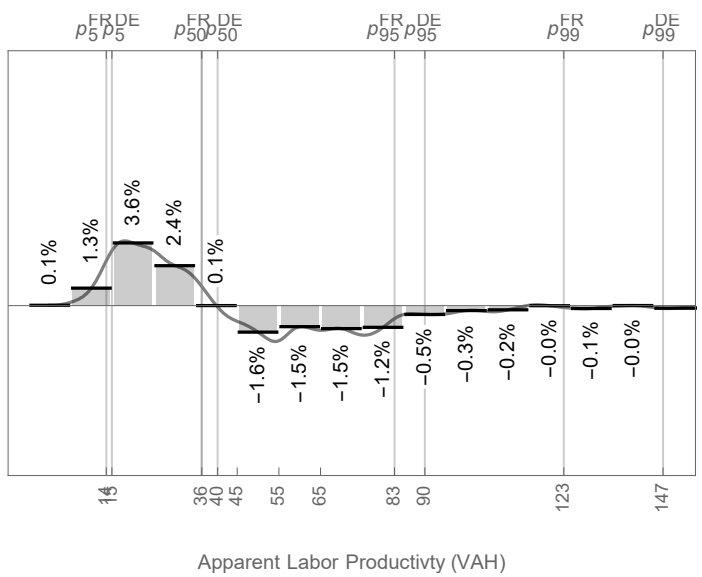

(b) Difference in probability density France vs. Germany (2009-2013)

Figure 4: Difference in TFP distribution - France vs. Germany

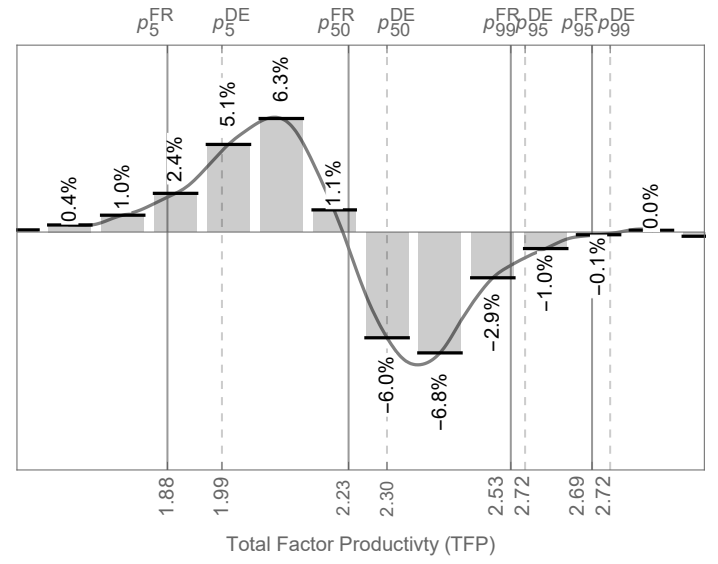

(a) Difference in probability density Franc (2003-2017)

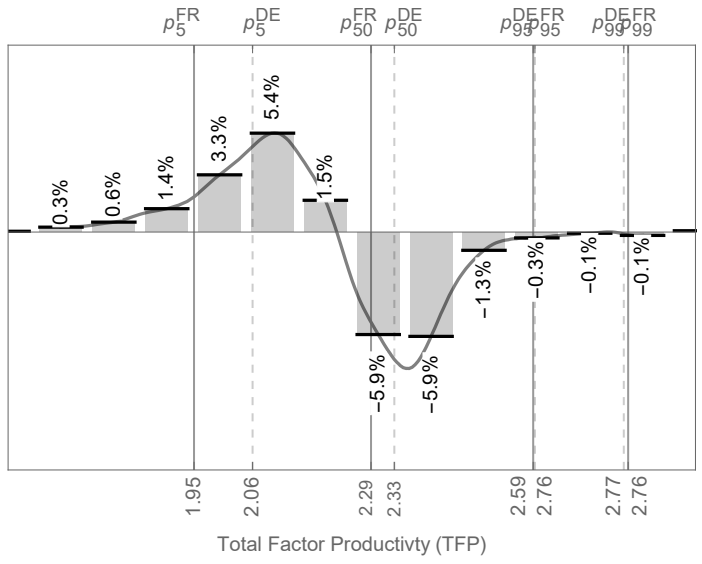

(b) Difference in probability density France vs. Germany (2009-2013) 
declining manner.

A more detailed look at Figure $3 \mathrm{a}$ also reveals the origins of the stochastic dominance by Germany in the first period. The relative share of below-median firms was about $15 \%$ higher in France in period 1. This is tantamount to saying that Germany, relative to France, has $15 \%$ more firms with an above-median apparent labor productivity.

French and German firm productivity levels converged in the post-recession period. The difference in PDFs approached the horizontal axis from below as much as from above. The gap decreased at every percentile of the productivity distribution. For instance, the surplus of French firms in the bottom percentiles (i.e. below the German median) decreased to $8.6 \%$ in $2009-2013$ (it was $14 \%$ before the recession, see above). Moreover, the underrepresentativeness of French firms in the right tail of the distribution (e.g. between the German median and the German 95th percentile) fell to $-7.6 \%$ (it was $-13 \%$ between 2003 and 2007). Overall, this indicates that between the two periods, the French distribution of value added per hour shifted more to the right than the German one, thus reducing, although not eliminating, the stochastic dominance of the latter.

Table 6 helps to see the above-mentioned distribution shifts more clearly. The first panel of the table reports, respectively for France and Germany, the values of different percentiles of the VAH distribution and their difference across the two periods analyzed. Moreover, it calculates the difference across periods. The table also reports the values of the central moments of the distribution (mean, standard deviation, skewness and kurtosis). The observed convergence in labor productivity was generated by a more robust increase in VAH at French firms. Labour productivity increased more in France on average $16.5 \%$ vs. $7.4 \%$ in Germany) as well as for firms localized at every percentile of the productivity distribution (cf. 3rd and 6th column of Table 6). The growth difference was especially large at the median (21.6\% in France vs. $10.1 \%$ in Germany) and at the 90th and 95th percentiles (respectively $15.9 \%$ and $14.0 \%$ in France vs. $9.0 \%$ and $4.7 \%$ in Germany).

Furthermore, the post-recession period was characterized - in both countries - by a reduction in productivity asymmetries across manufacturing firms. The standard deviation, the skewness and the excess kurtosis all significantly decreased in that period. The magnitude of the fall in the skewness was especially relevant (resp. 51\% in France and 91\% in Germany). ${ }^{7}$

\footnotetext{
${ }^{7}$ Productivity dispersion among firms is often taken as an indicator of the efficiency of the market selection process (see e.g. Hsieh and Klenow, 2018; Bartelsman et al., 2013; Bartelsman and Wolf, 2018). In this perspective, the reduction in the higher moments of the productivity distribution seems to indicate that the post
} 
Table 6: Summary statistics of productivity distributions (P1 vs. P2)

\begin{tabular}{|c|c|c|c|c|c|c|}
\hline & \multicolumn{3}{|c|}{ France } & \multicolumn{3}{|c|}{ Germany } \\
\hline & 2003-2007 & 2009-2013 & $\triangle \mathrm{VAH}$ in $€$ & $2003-2007$ & $2009-2013$ & $\Delta \mathrm{VAH}$ in $€$ \\
\hline$p_{1}$ & 3.9 & 4.2 & 0.3 & 9.1 & 4.9 & -4.1 \\
\hline$p_{5}$ & 12.3 & 13.6 & 1.3 & 15.9 & 14.9 & -1.0 \\
\hline$p_{10}$ & 15.4 & 17.6 & 2.2 & 19.6 & 19.5 & -0.1 \\
\hline$p_{50}$ & 30.0 & 36.5 & 6.5 & 36.6 & 40.3 & 3.7 \\
\hline$p_{90}$ & 59.0 & 68.4 & 9.4 & 69.2 & 75.4 & 6.2 \\
\hline$p_{95}$ & 72.6 & 82.8 & 10.1 & 86.0 & 90.0 & 4.0 \\
\hline$p_{99}$ & 119.7 & 123.4 & 3.7 & 141.8 & 147.2 & 5.4 \\
\hline$\mu$ & 35.2 & 41.0 & 5.8 & 42.1 & 45.2 & 3.1 \\
\hline$\sigma$ & 27.3 & 26.0 & -1.3 & 31.4 & 27.9 & -3.5 \\
\hline$\gamma$ & 112.2 & 45.2 & -67.0 & 246.9 & 22.1 & -224.8 \\
\hline \multirow[t]{2}{*}{$\omega$} & 7.1 & 4.0 & -3.1 & 3.8 & 2.7 & -1.1 \\
\hline & 2003-2007 & 2009-2013 & $\Delta \mathrm{TFP}$ & 2003-2007 & 2009-2013 & $\Delta \mathrm{TFP}$ \\
\hline$p_{1}$ & 1.605 & 1.595 & -0.010 & 1.783 & 1.888 & 0.105 \\
\hline$p_{5}$ & 1.885 & 1.952 & 0.067 & 1.988 & 2.062 & 0.075 \\
\hline$p_{10}$ & 1.974 & 2.039 & 0.065 & 2.074 & 2.132 & 0.058 \\
\hline$p_{50}$ & 2.227 & 2.286 & 0.059 & 2.300 & 2.330 & 0.031 \\
\hline$p_{90}$ & 2.466 & 2.521 & 0.056 & 2.496 & 2.526 & 0.030 \\
\hline$p_{95}$ & 2.534 & 2.593 & 0.059 & 2.561 & 2.596 & 0.035 \\
\hline$p_{99}$ & 2.688 & 2.772 & 0.085 & 2.722 & 2.764 & 0.043 \\
\hline$\mu$ & 2.218 & 2.272 & 0.054 & 2.291 & 2.328 & 0.037 \\
\hline$\sigma$ & 0.220 & 0.254 & 0.034 & 0.181 & 0.171 & -0.010 \\
\hline$\gamma$ & 13.183 & 25.393 & 12.209 & 5.075 & 7.397 & 2.321 \\
\hline$\omega$ & -1.426 & -2.925 & -1.499 & -0.258 & -0.368 & -0.110 \\
\hline
\end{tabular}

$p_{x}: x^{\text {th }}$ percentile; $\mu$ : mean; $\sigma:$ standard deviation; $\gamma:$ skewness; $\omega:$ kurtosis. 
As we already mentioned in the previous section, VAH comparisons do not account for differences in the rate of factors utilization across countries. Accounting for these differences can especially be relevant following a recession, as the latter may lead to important adjustments in production factors, e.g. by triggering labor hoarding but also by slowing down the rate of capital accumulation. For these reason, we repeat our comparative analysis of the pre- and post-recession distributions by employing TFP as a productivity measure (see Figure 4 and the bottom panel of Table 6). Results are similar to those discussed in the case of apparent labor productivity. First, Germany had a stochastic dominance also in terms of TFP before the Great Recession. Second, similarly to the distributions of $\mathrm{VAH}$, the dominance of Germany originated from an over-representation of French firms below the median productivity level, and by under-representation between the median and the 95th percentile. Third, also firm TFP levels in the two countries become closer after the Great Recession, although the convergence in TFP was less articulate as in the case of VAH. Again, the convergence was due to the stronger productivity growth of French firms, especially those located in the higher percentiles of the distribution (cf. third and sixth column of Table 6). It must be stressed, however, that the magnitude of the TFP gap in the first period was much smaller with respect to what we observed in the case of VAH. For instance, in period 1 the difference in TFP levels at the median was 7\% (compared to $20 \%$ in the case of VAH), and of only about $3 \%$ at the 95 th and 99th percentiles (while it was respectively $15 \%$ and $18 \%$ when using VAH). As a result, the convergence in TFP productivity levels was almost complete in the post-recession period. A median French firm became only $4 \%$ less productive than a median German firm, whereas the gap was basically nil $(0.08 \%)$ and in favor of French firms at the 99th percentile. Finally, the post-recession did not result in a significant reduction of productivity dispersion among firms that we observed when using VAH. On the contrary, the asymmetry in the distribution (measured by the skewness) increased by a factor of 2 in Germany and by a factor of 12 in France! In turn this indicates that the post-recession phase was characterized by a longer right tail of the TFP productivity distribution in both countries, and thus by a wider gap between the most productive firms and all the others.

Great recession period was characterized by an increase in market efficiency both in France and in Germany. 


\section{Microeconomic drivers of the Franco-German productivity gap}

This Sections aims to single out the role of allocative efficiency, structural change, firm size and export intensity in determining changes in productivity differentials between France and Germany. In the following Sections, we perform a decomposition exercise that explains productivity growth differentials. In Section 6.2, we carry out a decomposition analysis which allows us to measure the contributions sectoral efficiency gains vs. structural change in explaining productivity growth. Finally in Section 6.3, we study the contributions of firms with different sizes and export intensity.

\subsection{The role of allocative efficiency}

In this Section, we explore the role of allocative efficiency in order to document the role of resources allocation in explaining differences in productivity levels across the two countries. We start by defining aggregate productivity $\Pi$ at time $t$ as

$$
\Pi_{t}=\sum_{p, z} \pi_{p z, t} s_{p z, t}
$$

where $p$ and $z$ stand for percentile $p, p \in\{1, \ldots, 100\}$ of industry $z, z \in\{1, \ldots, Z\}$, respectively. Variable $\pi$ refers to efficiency, using either the log transformed values of value added per hour or total factor productivity. Variable $s$ refers to the value added share of percentile $p$ of industry $z$ over the whole manufacturing sector such that $s_{p z}=\mathrm{VA}_{p z} / \sum_{p, z} \mathrm{VA}_{p z}$. Following Olley and Pakes (1996), we decompose aggregate productivity into a first component corresponding to unweighted productivity and a second one corresponding to the correlation between market shares and productivity. The latter is called static allocative efficiency because it measures the extent to which resources are allocated efficiently in a given period across firms with heterogeneous productivity levels. The following equation illustrates the concept:

$$
\Pi_{t}=\sum_{p, z} \pi_{p z, t} s_{p z, t}=\bar{\pi}_{t}+\sum_{P, Z}\left(s_{p z, t}-\bar{s}_{t}\right)\left(\pi_{p z, t}-\bar{\pi}_{t}\right)
$$

where $\bar{s}_{t}$ and $\bar{\pi}_{t}$ represent the arithmetic mean of value added shares and productivity, respectively. The term $\Pi_{t}$ denotes aggregate productivity as a weighted sum of firmlevel productivity in year $t$ using value added shares $\left(\theta_{i t}\right)$ as weights. Equation (3) tells us that the weighted average productivity level can be decomposed as the sum of the 
unweighted average productivity $\bar{\pi}_{t}$ and a so-called covariance term equal to the product of the demeaned market shares $\left(\left(s_{p z, t}-\bar{s}_{t}\right)\right)$ and demeaned firm productivity levels $\left(\pi_{p z, t}-\bar{\pi}_{t}\right)$. In plain words, the first component captures the contribution to productivity from gains in firms' efficiency, while the covariance term measures the contribution of allocative efficiency. To understand why, suppose that market shares were allocated randomly. Then the covariance term in the second component of the above equation would be zero, and aggregate productivity would simply be equal to unweighted productivity. A non-zero covariance indicates the contribution to aggregate productivity from the allocation of market shares across firms with heterogeneous productivity levels. In particular, a positive (negative) covariance indicates that firms with an above average productivity have also above average market shares while the opposite occurs for firms with productivity levels below average. ${ }^{8}$

Figure 5: Allocative Efficiency as a percentage of aggregate productivity

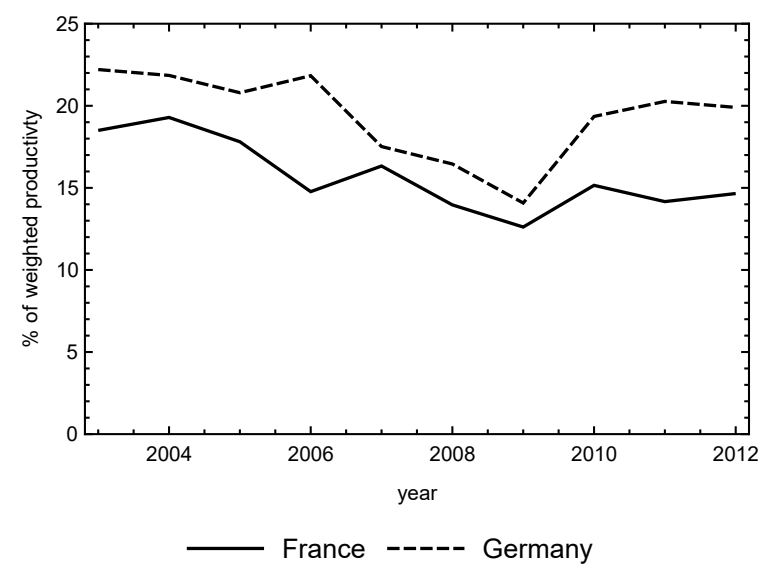

(a) VAH

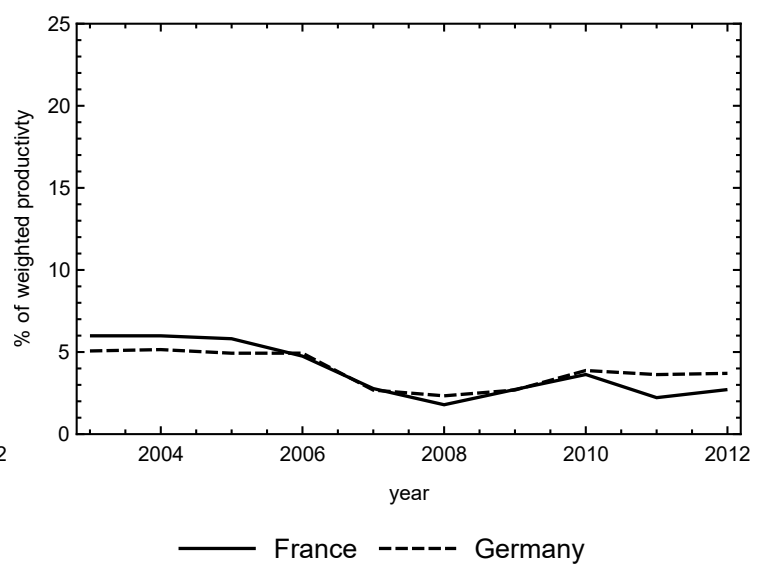

(b) TFP

Table 7 and Figure 5 show the results of the above decomposition exercise on aggregate productivity computed both as value added per hour (VAH) and total factor productivity

\footnotetext{
${ }^{8}$ The static efficiency measured by the Olley and Pakes (1996) decomposition can be contrasted to dynamic allocative efficiency methods, proposed e.g. in Melitz and Polanec (2015); Foster et al. (2006) that takes into account also the contribution of the entry-exit of firms. Entry and exit can explain a sizeable part of the process of market reallocation, something that is clearly not captured by the Olley-Pakes (OP) decomposition. Despite this important shortcoming, the OP decomposition approach is still useful to illustrate differences in the efficiency of the allocation of output across country and/or industries. Moreover, it is robust to the impact of distortions in the resources reallocation process on aggregate productivity levels (see Bartelsman et al., 2013. for a discussion).
} 
Table 7: Allocative Efficiency as a percentage of aggregate productivity

\begin{tabular}{lrrrrrrrrrr} 
VAH & 2003 & 2004 & 2005 & 2006 & 2007 & 2008 & 2009 & 2010 & 2011 & 2012 \\
\hline FR & $19 \%$ & $19 \%$ & $18 \%$ & $15 \%$ & $16 \%$ & $14 \%$ & $13 \%$ & $15 \%$ & $14 \%$ & $15 \%$ \\
DE & $22 \%$ & $22 \%$ & $21 \%$ & $22 \%$ & $18 \%$ & $17 \%$ & $14 \%$ & $20 \%$ & $20 \%$ & $20 \%$ \\
\hline$\Delta$ FR - DE & $-4 \%$ & $-3 \%$ & $-3 \%$ & $-7 \%$ & $-1 \%$ & $-3 \%$ & $-2 \%$ & $-4 \%$ & $-6 \%$ & $-5 \%$ \\
& & & & & & & & & & \\
\hline
\end{tabular}

\begin{tabular}{lrrrrrrrrrr} 
TFP & 2003 & 2004 & 2005 & 2006 & 2007 & 2008 & 2009 & 2010 & 2011 & 2012 \\
\hline FR & $6 \%$ & $6 \%$ & $6 \%$ & $5 \%$ & $3 \%$ & $2 \%$ & $3 \%$ & $4 \%$ & $2 \%$ & $3 \%$ \\
DE & $5 \%$ & $5 \%$ & $5 \%$ & $5 \%$ & $3 \%$ & $2 \%$ & $3 \%$ & $4 \%$ & $4 \%$ & $4 \%$ \\
\hline$\Delta$ FR-DE & $1 \%$ & $1 \%$ & $1 \%$ & $0 \%$ & $0 \%$ & $-1 \%$ & $0 \%$ & $0 \%$ & $-1 \%$ & $-1 \%$ \\
\hline \hline
\end{tabular}

(TFP). Before the Great Recession, the contribution of allocative efficiency to aggregate productivity growth was about $20 \%$ both in France and in Germany if we consider VAH. That contribution drops to a much smaller value when we take TFP (between 5\% and 6\%). These findings are similar to the ones obtained by recent works (see e.g. The CompNet Task Force, 2014, Niesr et al., 2016, Bartelsman et al., 2013) which also point to France and Germany as two countries characterized by low levels of allocative efficiency (in contrast to countries in Eastern Europe). Furthermore, allocative efficiency was higher in Germany than in France if we consider labor productivity, although the difference is in general small (reaching a peak of 7\% in 2006), and very small with TFP (they are never larger than 1\% in magnitude). Finally, the contributions of allocative efficiency decreased in both countries until 2007. In particular, allocative efficiency almost recovered its pre-recession values in Germany, at least when we take VAH, while it basically remained at same values as in 2007 in France.

\subsection{Productivity growth and structural change}

Productivity growth is not a balanced and smooth process. It is always associated with structural change, and thus with the growth of some industries and the shrinkage or disappearance of others (see e.g. Rodrik, 2016; Herrendorf et al., 2014). The reallocation of value added across industries resulting from structural change may significantly affect productivity growth within a country (see e.g. Duarte and Restuccia, 2010; Cantner and 
Krüger, 2008; Peneder, 2003). We thus begin our analysis of the drivers of aggregate productivity growth in France and Germany by evaluating the contributions of sectoral efficiency gains vs. structural change.

Recall that aggregate productivity $\Pi$ at time $t$ as $\Pi_{t}=\sum_{z=1}^{Z} \sum_{p=1}^{P} \pi_{p z, t} s_{p z, t}$. Define aggregate productivity growth for all manufacturing as the relative change in aggregate productivity $\left(\Delta \Pi=\left(\frac{1}{t-b}\right) \cdot\left(\Pi_{t}-\Pi_{b}\right)\right)$ of a given period compared to the productivity level for some base period $b\left(\pi_{b}, b<t\right) .{ }^{9}$ Following Fagerberg (2000), we decomposes aggregate productivity growth in manufacturing into three components: a "within" component, capturing the contribution from productivity growth within industries, a "between" component, capturing the contribution from value added shares reallocation across industries and, finally, an "interaction" term that reflects market efficiency by measuring the correlation between productivity growth and changes in value added shares. The decomposition reads:

$$
\Delta \Pi=\left(\frac{1}{t-b}\right) \sum_{p, z}(\underbrace{\Delta \pi_{p z} s_{p z, b}}_{\mathrm{I}}+\underbrace{\pi_{p z, b} \Delta s_{p z}}_{\mathrm{II}}+\underbrace{\Delta \pi_{p z} \Delta s_{p z}}_{\mathrm{III}})
$$

Our aim is to explore the drivers of location shifts in the productivity level distributions analyzed in the previous sections. For this reason, we compute the overal growth rate of productivity as the relative change between the mean productivity level of the post-recession period (2009-2013) and the mean productivity level of the pre-recession phase (2003-2007). Component (I) quantifies the contribution of productivity gains $\left(\Delta \pi_{z}\right)$ in overall growth. Component (II) captures the role of structural change in the productivity growth process, as it measures the contribution of market share reallocation across industries and it weights industry $z$ 's productivity by the change in the share of industries in total value added. Finally, component (III) corresponds to the interaction term and, if positive, indicates that more productive industries also increase their market share.

Table (8) shows the results of the decomposition exercise by using total factor productivity (TFP). We focus on TFP only as it provides a more complete picture of changes in productivity by taking factors utilization into account. ${ }^{10}$

The first line of the table shows the total contributions of the different components highlighted in Equation 4 as well as the aggregate productivity growth rate. Overall, aggregate TFP growth was higher in France than in Germany ( $0.435 \%$ vs. $0.257 \%$ growth), a result that explains the convergence in productivity levels we documented in the previous

\footnotetext{
${ }^{9}$ The fraction $\frac{1}{t-b}$ implies that we express a compound annual growth rate.

${ }^{10}$ Appendix A also reports the results using labor productivity growth.
} 
Table 8: Structural Change and Total Factor Productivity Growth

\begin{tabular}{|c|c|c|c|c|c|}
\hline ISIC & Sector Name & $\Delta \pi \times s$ & $\pi \times \Delta s$ & $\Delta \pi \times \Delta s$ & $\Delta$ tot \\
\hline & & \multicolumn{4}{|c|}{ France } \\
\hline $10-33$ & All Manufacturing & 0.798 & -0.482 & 0.12 & 0.435 \\
\hline 10 & Food products & -0.015 & 0.766 & -0.003 & 0.749 \\
\hline 17 & Paper and paper products & 0.026 & -0.016 & 0.000 & 0.010 \\
\hline 20 & Chemicals and chemical products & -0.034 & 0.304 & -0.002 & 0.269 \\
\hline 22 & Rubber and plastic products & 0.120 & 0.380 & 0.010 & 0.510 \\
\hline 23 & Other non-metallic mineral products & 0.039 & 0.024 & -0.007 & 0.056 \\
\hline 24 & Basic metals & 0.007 & -0.674 & 0.005 & -0.662 \\
\hline 25 & Fabricated metal products & 0.106 & 0.374 & 0.011 & 0.490 \\
\hline 26 & Computer, electronic and optical products & 0.198 & 0.539 & 0.040 & 0.777 \\
\hline 27 & Electrical equipment & 0.130 & 0.554 & 0.039 & 0.724 \\
\hline 28 & Machinery and equipment n.e.c. & 0.123 & -0.881 & -0.017 & -0.776 \\
\hline 29 & Motor vehicles, trailers and semi-trailers & -0.019 & -2.230 & 0.031 & -2.218 \\
\hline 32 & Other manufacturing & 0.018 & 0.056 & 0.002 & 0.075 \\
\hline \multirow[t]{2}{*}{33} & Repair and installation & 0.099 & 0.321 & 0.012 & 0.432 \\
\hline & & \multicolumn{4}{|c|}{ Germany } \\
\hline $10-33$ & All Manufacturing & 0.150 & -0.026 & 0.134 & 0.257 \\
\hline 10 & Food products & -0.037 & -0.196 & 0.007 & -0.226 \\
\hline 17 & Paper and paper products & 0.018 & -0.017 & -0.001 & 0.001 \\
\hline 20 & Chemicals and chemical products & -0.003 & 0.213 & -0.002 & 0.208 \\
\hline 22 & Rubber and plastic products & 0.019 & 0.020 & 0.000 & 0.039 \\
\hline 23 & Other non-metallic mineral products & 0.028 & -0.033 & 0.000 & -0.005 \\
\hline 24 & Basic metals & -0.036 & -0.482 & 0.008 & -0.510 \\
\hline 25 & Fabricated metal products & 0.014 & 0.000 & 0.000 & 0.014 \\
\hline 26 & Computer, electronic and optical products & 0.080 & 0.568 & 0.036 & 0.684 \\
\hline 27 & Electrical equipment & 0.136 & 0.994 & 0.046 & 1.177 \\
\hline 28 & Machinery and equipment n.e.c. & -0.078 & -0.996 & 0.009 & -1.066 \\
\hline 29 & Motor vehicles, trailers and semi-trailers & 0.011 & -0.016 & 0.010 & 0.005 \\
\hline 32 & Other manufacturing & 0.017 & 0.017 & 0.004 & 0.038 \\
\hline 33 & Repair and installation & -0.020 & -0.100 & 0.017 & -0.103 \\
\hline
\end{tabular}

The aggregate productivity growth rate is computed as the relative change in average total factor productivity between the period 2009-2013 and the period 2003-2007. For both years, all variables are computed as moving average with a two-year window around the target year. Value-added shares $s$ are used for computations. 
sections. Growth was mostly driven by within-sectors efficiency gains in both countries (0.798\% growth in France vs. $0.150 \%$ in Germany), whereas structural change gave a negative contribution. Finally, the interaction term is small but positive pointing to the reallocation of market shares towards sectors with higher productivity growth.

The dominant role of within sector efficiency gains at the aggregate level is in line with a large set of previous contributions, which also point to the importance productivity dynamics (see e.g. Bartelsman and Doms, 2000; Syverson, 2011; Dosi et al., 2015). Table 8 also shows the different contributions to TFP growth for each manufacturing industries. These statistics allows one to evaluate which industries contributed most to aggregate productivity growth. They also help to identify the role played by within-sector efficiency gains vs. market share reallocation in driving sectoral productivity growth. Their analysis reveals first that the growth advantage of France spotted at the aggregate level was also systematic across 2-digit manufacturing sectors. Indeed, with just two exceptions ("Chemicals and chemical products" and the automobile industry) all manufacturing sectors scored higher TFP growth in France than in Germany. Furthermore, growth rates vary widely across sectors with few sectors displaying large positive or negative growth rates relative to others. The largest positive contribution to growth in France come from sectors like "Computer, electronic and optical products" (0.777\% growth), "Food products" (0.749\% growth), and "Electrical Equipment" ( $0.724 \%$ growth). At other extreme, the motor vehicles industry ("Motor Vehicles, trailers and semi-trailers") displayed a significantly negative growth $(-2.218 \%)$. Sectoral TFP growth rates are also asymmetric in Germany as well. The leading sector in terms of productivity is the "Electrical Equipment" with a growth rate of $1.177 \%$, whereas the "Machinery and Equipment" sector is the one displaying the largest negative growth $(-1.066 \%)$.

What is the role of efficiency gains vs. market reallocation in explaining the above sectoral growth rates? In sharp contrast with the results at the aggregate level, Table 8 indicates that sectoral productivity growth rates were mostly driven by changes in value added shares. With very few exceptions, the market reallocation component dominated the efficiency gains one. Moreover, the dominance of the structural change component is stronger in sectors displaying the largest growth rates (either positive or negative). For instance in France, the large growth rates of the computer and electrical equipment sectors were largely driven by the robust increase in the value added share (resp. $0.539 \%$ and $0.554 \%$ growth), which added to the positive within sector efficiency gains. Likewise, the strong growth in the value added share $(0.766 \%$ growth) allowed productivity in the "Food product" sector to grow despite a decrease in within sector efficiency $(-0.015)$. Finally, 
the large negative growth rate of the motor vehichles sector were also driven by a large decrease in the share of value of added of this sector $(-2.230 \%$ growth vs. $-0.019 \%$ variation in efficiency). Similar patterns are observed in Germany where the largest productivity variations observed in the electrical equipment or machinery and equipment sector were again the result of signficiant (resp. positive and negative) variations in the value added share of these sectors.

To sum up, the convergence of firm productivity levels between France and Germany observed after the Great Recession was driven by the larger productivity growth of French firms, that was systematic across manufacturing sectors. Furthermore, both in France and in Germany productivity growth was of the "mushroom" type (see Harberger, 1998) with few sectors contributing (positively or negatively) to overall productivity growth with disproportionately large growth rates. In addition, those large rates are mostly explained by market reallocation across sectors. This last result reveals the presence of an interesting composition effect. At the aggregate level, efficiency gains contributed the most to overall productivity growth whereas market shares reallocation mostly explains productivity growth at the sectoral level.

\subsection{Productivity growth, firm size and export intensity}

The last decomposition exercise we carry out accounts for the contribution of firms with different sizes or export intensity to productivity growth. Several works have pointed to the key role of these two characteristics in the determination of firm productivity. On the one hand, firm size has been related to the intensity of R\&D investments (see e.g. Cohen et al., 1987) but also to the tightness of firm borrowing contraints (see e.g. Gopinath et al., 2017). On the other hand, a large empirical literature has highlighted that exporting firms also display higher productivity with respect to non-exporting ones (see e.g. Bernard et al., 2007).

More formally, we classify firms into separate size or export intensity classes and we decompose the average aggregate productivity growth rate between the post- and prerecession period by using the same decomposition formula used in Section 6.2.

$$
\Delta \Pi=\left(\frac{1}{t-b}\right) \sum_{p, w}(\underbrace{\Delta \pi_{p w} s_{p w, b}}_{\mathrm{I}}+\underbrace{\pi_{p w, b} \Delta s_{p w}}_{\mathrm{II}}+\underbrace{\Delta \pi_{p w} \Delta s_{p w}}_{\mathrm{III}})
$$

with the difference that $w$ now refers to a specific class of firm size or export intensity. 
We use three classes for firm size: "small", including firms with less than 250 employees in full-time equivalent on average, "medium", including firms with size larger than 250 employees and smaller than 500 employees and, finally, a "large" firms class, with firms above 500 employees. For the classification by export intensity, we use the share of firm exports over their total output. Again, we identify three classes, the first one including firms with "weak" export intensity, and exporting less than $20 \%$ of their total output. A second class of firms with "medium" intensity comprises firms with an export share between $20 \%$ and $50 \%$ of their total output. The final class of "strong" exporters includes instead firms that sell abroad more than a half of their total output.

Table 9 reports the results of the above decomposition exercise for each size and export intensity class.Similarly to Section 6.2 we present the results for the TFP only and we refer the reader to the appendix for the presentation of the results on labor productivity. The table show the results of the decomposition for France and Germany, and it also reports the differences in productivity contributions between the two countries for the sake of comparison. In addition, for consistency reasons with the previous exercises, the first three lines of the table also show results by aggregating firms across all size and export intensity classes.

Let us discuss overall productivity growth contributions by size classes first. Table 9 reveals that the largest contribution to productivity growth came from large firms both in France and Germany, and it was especially larger in the latter country (nearly 3.6\% total growth vs $2 \%$ growth in France, cf. the last column of the table). In contrast, the overall contribution of small firms was negative in both countries, particularly in France (nearly $-3 \%$ growth vs. $-1.2 \%$ growth in Germany). Finally, the contribution of medium-sized firms was positive in France but negative in Germany. It is therefore clear that the catching up of French firms was mainly the result of the superior growth performance of this last group of firms while, on the contrary, German small and large firms widened their gap with respect to similar firms in France.

The decomposition of total growth contributions (first 3 columns of Table 9) allows one to shed lights on the above differences across size classes. Remarkably, small firms scored the largest efficiency gains in France (0.6\% contribution) but experienced a large reduction of value added shares ( $-3.5 \%$ contribution) compared to firms of larger sizes. Thus, in France small firms faced significant obstacles to growth despite being more efficient than medium and large firms in the post-recession period. Contrary to Francen, large firms scored the largest increase in efficiency gains in Germany (roughly $1 \%$ contribution). They 
Table 9: Firm Size, Firm Export Intensity and Total Factor Productivity Growth

\begin{tabular}{lcccc}
\hline & $\Delta \pi \times s$ & $\pi \times \Delta s$ & $\Delta \pi \times \Delta s$ & $\Delta$ tot \\
\hline & All firms & & & \\
FR & 0.798 & -0.482 & 0.120 & 0.435 \\
DE & 0.150 & -0.026 & 0.134 & 0.257 \\
$\Delta$ FR-DE & 0.648 & -0.456 & -0.014 & 0.178 \\
\hline
\end{tabular}

Firm Size

\begin{tabular}{llcccc} 
FR & Small & 0.632 & -3.463 & -0.001 & -2.832 \\
& Medium & 0.143 & 0.999 & 0.081 & 1.223 \\
& Large & 0.023 & 1.981 & 0.040 & 2.045 \\
& & & & & \\
DE & Small & 0.022 & -1.272 & 0.017 & -1.233 \\
& Medium & 0.038 & -2.157 & 0.040 & -2.079 \\
& Large & 0.089 & 3.402 & 0.077 & 3.569 \\
& & & & & \\
\multirow{2}{*}{$\Delta$ FR-DE } & Small & 0.610 & -2.191 & -0.018 & -1.599 \\
& Medium & 0.104 & 3.157 & 0.041 & 3.301 \\
& Large & -0.066 & -1.421 & -0.037 & -1.524 \\
\hline
\end{tabular}

\section{Export Intensity}

\begin{tabular}{llcccc} 
FR & Weak & 0.162 & -0.143 & -0.010 & 0.009 \\
& Medium & 0.428 & 0.680 & 0.111 & 1.220 \\
& strong & 0.207 & -1.02 & 0.019 & -0.794 \\
& & & & & \\
DE & Weak & -0.012 & 0.033 & 0.032 & 0.053 \\
& Medium & 0.087 & 2.236 & 0.044 & 2.367 \\
& Strong & 0.075 & -2.295 & 0.058 & -2.162 \\
& & & & & \\
\multirow{2}{*}{$\Delta$ FR-DE } & Weak & 0.174 & -0.175 & -0.042 & -0.043 \\
& Medium & 0.342 & -1.556 & 0.067 & -1.147 \\
& Strong & 0.132 & 1.275 & -0.039 & 1.368 \\
\hline
\end{tabular}

The aggregate productivity growth rate is computed as the relative change in average total factor productivity between the period 2009-2013 and the period 2003-2007. Classification by firm size: small: firms with less than 250 employees in full-time equivalents on average; medium: firms with more than 250 and less than 500 employees in full-time equivalents; large: firms with at least 500 employees. Classification by export intensity: weak: firms exporting less than $20 \%$ of their total output; medium: firms exporting between $20 \%$ and $50 \%$ of their total output; strong: firms exporting more than $50 \%$ of their total output. 
were also able to significantly increase their market share (3.4\% contribution) with respect to medium and large firms in the country.

The bottom panel of Table 9 shows instead productivity growth rates by export intensity class, as well as their decomposition. Firms with medium export intensity displayed the largest productivity growth rates both in France and in Germany whereas productivity growth of strong exporters was negative. However, the fall in productivity in this export intensity class was larger in Germany. The result is that strong exporters actually contributed to France's productivity catching up in the post-recession period. Finally, and not surprisingly, weak exporters displayed a modest productivity growth in both countries. Table 9 also reveals that the superior growth performance of medium exporters is explained both by larger gains in efficiency and by the increase in value added shares. In contrast, the significant fall in market shares of strong exporters (especially in Germany) overwhelmed their increase in efficiency. Overall, it appears that - both in France and Germany - medium exporters were much more resilient than strong exporters to the strains that Great Recession imposed on global trade.

\section{Discussion}

Let us now put the different threads together and discuss the findings obtained so far in relation to the existing literature.

First, our results indicate that gaps in firm productivity levels are sentitive to the measure used. Although we detect a systematic advantage for German firms with both labor productivity and TFP, their magnitude was clearly smaller with the latter measure. In addition firm productivity gaps across the percentiles of the distributions were different according to the productivity measure used. Differences in labor productivity increased with productivity percentiles, and they were thus highest for most productive firms, whereas the opposite was observed for TFP differences. Finally, the evolution of higher moments of the distribution was not the same across productivity measures. In particular, the post-recession phase was characterized by a significant reduction in dispersion and skewness in both France and Germany when using VAH while the opposite was observed with TFP. The above results point to the role played by factors utilization in explaining productivity differences across countries. Recently, differences in factor utilization have been employed to explain the productivity slowdown of Southern countries like Spain, Italy and Greece (Gopinath et al. 2017). Our results indicate that factor utilization may played a significant role in 
determining the productivity gaps of France and Germany. In particular, Germany's response to the crisis was characterized by significant labor hoarding (see e.g. Burda and Hunt, 2011; Bohachova et al., 2011; Möller, 2010), and this may have contributed to a large extent to hamper productivity growth of German firms and favored the catching-up by French firms in the post-recession phase.

Second, and relatedly, our results highlight that accounting for firm heterogeneity provides a much more complete picture of the origins and evolution of productivity differences across countries with respect to the one provided by the comparison of simple averages. In particular, our analysis of the evolution of distributions over time reveals that the convergence in productivity levels observed in the post-recession phase is mostly driven by firms above the productivity median that exhibited larger growth in France with respect to their German counterparts (see also Andrews et al., 2016, for similar findings in OECD countries).

Third, our results have implications for the vast literature on resources allocation and productivity (see e.g. Hsieh and Klenow, 2009; Bartelsman et al., 2013; Gopinath et al., 2017; Bartelsman and Wolf, 2018) On the one hand, the small contribution measured by the Olley-Pakes allocative efficiency indicator (cf. Section 6.1) and the large contribution from within sectors efficiency gains at the aggregate level (cf. Section 6.2) point to a minor role of allocative efficiency in explaining the firm productivity gaps between France and Germany, especially if one takes into account TFP. On the other hand, other findings we obtained point exactly in the opposite direction and they highlight instead the contribution of the resource allocation process as well as of frictions in this process. This, for instance, is the case of the contribution of sectoral shares reallocation which drives most of the post-recession productivity growth at the sectoral level in the two countries (see Section 6.2). It is also the case of the negative valued added growth experienced by small firms in France in the post-recession period, despite their larger efficiency gains. Finally, some indicators of allocative efficiency displayed significant variation across the productivity measure used. In particular, the post-recession phase was characterized by a significant reduction of dispersion in labor productivity levels both in France and Germany whereas the opposite was detected with TFP. Overall, these results highlight that the relation between resource allocation and productivity is too complex to be fully captured by a single indicator.

Our results can also be related to the empirical literature on the cleansing effects of recessions and more in general on the impact that major crises (including the last ongoing crisis related to the Covid-19 pandemics) can have on productivity dynamics. The fact 
that the allocative efficiency steadily decreased both in France and in Germany until the Great Recession outburst and it recovered only several years later (and not very much with TFP) is in contrast to the cleansing effect hypothesis. Moreover, such a result is in line with the findings of recent works (see Foster et al., 2016; Bartelsman et al., 2018b), which higlight that the Great Recession was indeed not a moment of big resource allocation. These works also point to the impact the fall in global trade and of credit constraints as the reasons for the lack of productivity enhancing reallocation during the Great Recession. Our evidence brings support to these hypotheses. In particular, small firms, which are also those typically more affected by credit constraints, displayed negative value added growth in the post-recession phase compared to medium and large firms (especially in France). Likewise firms with higher export intensity were heavily affected during the crisis, and they lost market shares at the expenses of medium exporters.

Finally, our results have also implications for the debate about the origins of differences in competitiveness in Europe. In particular, the fact that the productivity levels of manufacturing firms in France and Germany converged after the Great Recession corroborates the idea that the source of the productivity gap between these two countries may lie in the rise of the share of low-productivity service sectors, that is more pronounced in France in the last decades (Martin et al., 2019). Meanwhile, as international trade mostly concerns manufacturing goods, our results about convergence in firm productivity levels between France and Germany indicate that the sources of the persistent gap in trade performance between the two countries have little to do with firm differences in efficiency and must instead be searched in the different evolution of factors of governing non-price competitiveness (see e.g. Le Moigne and Ragot, 2015).

\section{Conclusion}

We have analyzed differences in productivity levels between France and Germany, based on firm-level large-scale data bases covering most of the manufacturing industry. We built comparable productivity measures and we studied the whole distribution of productivity levels in the two countries. We also studied how the aforementioned distributions changed in response to the Great Recession. Finally, we examined the drivers of firm gaps in productivity between the two countries, by focusing in particular on the role of structural change, allocative efficiency, firm size and export intensity.

Our results reveal an overall advantage of Germany over France in the manufacturing 
industry over the period 2003-2013. Nevertheless, the gap shrank after the Great Recession and it almost faded away in terms of total factor productivity. This result corroborates the idea that the origins of differences in competitiveness between the two countries are not due to the productivity of manufacturing firms and must instead searched in the productivity of the service industry or in wage growth differentials or, finally, in non-price factors (see also Martin et al., 2019; Le Moigne and Ragot, 2015). Furthermore, our results militate against the idea the deep recessions are also major moments of productivity-enhancing market reallocation. At the same time, they also highlight the presence of important frictions in the market selection process hampring the growth of productive firms (especially small firms in France), and they also point to the need of considering several indicators when evaluating the degree of market efficiency of a country.

Our work could be extended at least in two directions. An obvious one is to study the evolution of the distribution of productivity levels also in the service industry. This industry nowadays accounts for the largest share of value added and employment in advanced economies and - as the analysis performed in this paper also seem to indicate - it is most probably the locus of productivity differentials among them. Furthermore, in this work we have only studied the factors related to shifts in location of the productivity levels distributions. However, we showed the post Great Recession period was characterized by significant shifts also in higher moments of those distributions. A second extension would thus involve studying the factors underlying the latter shifts, e.g. through decomposition analyses similar to the ones performed herein.

\section{Acknowledgements}

We thank without implicating them Margarita Lopéz-Forero and Angelo Secchi. The authors acknowledge the financial support of the European Union Horizon 2020 research and innovation programme under grant agreement No. 649186 (ISIGrowth). Access to French confidential firm-level data, on which this work is based, has been made possible within a secure environment offered by CASD - Centre d'accès sécurisé aux données (Ref. ANR-10EQPX-17). 


\section{References}

Aiginger, K., Horvath, T., and Mahringer, H. (2011). Why labour market response differed in the great recession: The impact of institutions and policy. Technical report, WIFO Working Papers.

Andrews, D., Criscuolo, C., and Gal, P. N. (2016). The best versus the rest: The global productivity slowdown, divergence across firms and the role of public policy. OECD Productivity Working Papers 5, OECD Publishing.

Ball, L. (2014). Long-term damage from the great recession in oecd countries. European Journal of Economics and Economic Policies: Intervention, 11(2):149-160.

Bartelsman, E., Hagsten, E., and Polder, M. (2018a). Micro moments database for crosscountry analysis of ict, innovation, and economic outcomes. Journal of Economics \& Management Strategy, 27(3):626-648.

Bartelsman, E., Haltiwanger, J., and Scarpetta, S. (2013). Cross-country differences in productivity: The role of allocation and selection. The American Economic Review, 103(1):305334.

Bartelsman, E., Haltiwanger, J., and Scarpetta1, S. (2004). Microeconomic evidence of creative destruction in industrial and developing countries. Policy Research Working Paper Series 3464, The World Bank.

Bartelsman, E., Lopez-Garcia, P., and Presidente, G. (2019). Labour reallocation in recession and recovery: Evidence for europe. National Institute Economic Review, 247(1):R32-R39.

Bartelsman, E., Scarpetta, S., and Schivardi, F. (2005). Comparative analysis of firm demographics and survival: evidence from micro-level sources in oecd countries. Industrial and corporate change, 14(3):365-391.

Bartelsman, E. J. and Doms, M. (2000). Understanding productivity: Lessons from longitudinal microdata. Journal of Economic literature, 38(3):569-594.

Bartelsman, E. J., Lopez-Garcia, P., and Presidente, G. (2018b). Cyclical and structural variation in resource allocation: evidence for europe. ECB Working Paper Series 2210, ECB. 
Bartelsman, E. J. and Wolf, Z. (2018). Measuring productivity dispersion. Oxford Handbook of Productivity Analysis.

Barth, E., Davis, J., Freeman, R., and Kerr, S. P. (2017). Weathering the great recession: Variation in employment responses, by establishments and countries. RSF: The Russell Sage Foundation Journal of the Social Sciences, 3(3):50-69.

Bellone, F., Kiyota, K., Matsuura, T., Musso, P., and Nesta, L. (2014). International productivity gaps and the export status of firms: Evidence from france and japan. European Economic Review, 70:56-74.

Bergeaud, A., Cette, G., and Lecat, R. (2016). Productivity trends in advanced countries between 1890 and 2012. Review of Income and Wealth, 62(3):420-444.

Bernard, A. B., Jensen, J. B., Redding, S. J., and Schott, P. K. (2007). Firms in international trade. Journal of Economic perspectives, 21(3):105-130.

Biddle, J. E. (2014). Retrospectives: the cyclical behavior of labor productivity and the emergence of the labor hoarding concept. Journal of Economic Perspectives, 28(2):197212.

Bohachova, O., Boockmann, B., and Buch, C. M. (2011). Labor Demand During the Crisis: What Happened in Germany? IZA Discussion Papers 6074, Institute of Labor Economics (IZA).

Burda, M. C. and Hunt, J. (2011). What explains the german labor market miracle in the great recession? Working Paper 17187, National Bureau of Economic Research.

Caballero, R. J. and Hammour, M. L. (1994). The cleansing effect of recessions. The American Economic Review, pages 1350-1368.

Caballero, R. J. and Hammour, M. L. (1996). On the timing and efficiency of creative destruction. The Quarterly Journal of Economics, 111(3):805-852.

Cantner, U. and Krüger, J. J. (2008). Micro-heterogeneity and aggregate productivity development in the german manufacturing sector. Journal of Evolutionary Economics, 18(2):119-133. 
Caves, D. W., Christensen, L. R., and Diewert, W. E. (1982). The economic theory of index numbers and the measurement of input, output, and productivity. Econometrica: Journal of the Econometric Society, pages 1393-1414.

Cohen, W. M., Levin, R. C., Mowery, D. C., et al. (1987). Firm size and r\&d intensity: A re-examination. Journal of Industrial Economics, 35(4):543-565.

Dosi, G., Grazzi, M., Tomasi, C., and Zeli, A. (2012). Turbulence underneath the big calm? the micro-evidence behind italian productivity dynamics. Small Business Economics, 39(4):1043-1067.

Dosi, G., Moschella, D., Pugliese, E., and Tamagni, F. (2015). Productivity, market selection, and corporate growth: comparative evidence across us and europe. Small Business Economics, 45(3):643-672.

Duarte, M. and Restuccia, D. (2010). The role of the structural transformation in aggregate productivity. The Quarterly Journal of Economics, 125(1):129-173.

Fagerberg, J. (2000). Technological progress, structural change and productivity growth: a comparative study. Structural change and economic dynamics, 11(4):393-411.

Fernald, J. G. (2015). Productivity and potential output before, during, and after the great recession. NBER macroeconomics annual, 29(1):1-51.

Force, C. T. (2014). Micro-based evidence of eu competitiveness: the compnet database. Working Paper Series 1634, European Central Bank.

Foster, L., Grim, C., and Haltiwanger, J. (2016). Reallocation in the great recession: cleansing or not? Journal of Labor Economics, 34(S1):S293-S331.

Foster, L., Haltiwanger, J., and Krizan, C. J. (2006). Market selection, reallocation, and restructuring in the us retail trade sector in the 1990s. The Review of Economics and Statistics, 88(4):748-758.

Good, D. H., Nadiri, M. I., and Sickles, R. C. (1996). Index number and factor demand approaches to the estimation of productivity. Technical report, National Bureau of Economic Research. 
Gopinath, G., Kalemli-Özcan, Ş., Karabarbounis, L., and Villegas-Sanchez, C. (2017). Capital allocation and productivity in south europe. The Quarterly Journal of Economics, 132(4):1915-1967.

Harberger, A. C. (1998). A vision of the growth process. The American Economic Review, 88(1):1-32.

Herrendorf, B., Rogerson, R., and Valentinyi, A. (2014). Growth and structural transformation. In Handbook of economic growth, volume 2, pages 855-941. Elsevier.

Hsieh, C.-T. and Klenow, P. J. (2009). Misallocation and manufacturing tfp in china and india. The Quarterly journal of economics, 124(4):1403-1448.

Hsieh, C.-T. and Klenow, P. J. (2018). The Reallocation Myth. Working Papers 18-19, Center for Economic Studies, U.S. Census Bureau.

Inklaar, R., Timmer, M., et al. (2009). Productivity convergence across industries and countries: The importance of theory-based measurement. Technical report, Groningen Growth and Development Centre, University of Groningen.

Jäger, K. (2016). Eu klems growth and productivity accounts 2016 release, statistical module1.

Le Moigne, M. and Ragot, X. (2015). France et Allemagne : une histoire du désajustement européen. Revue de l'OFCE, 0(6):177-231.

Martin, P., Blanchard, O., Boone, L., Cette, G., Criscuolo, C., Epaulard, A., Jean, S., Kyle, M., Ragot, X., Roulet, A., and Thesmar, D. (2019). Productivity and competitiveness: where does france stand in the euro zone? Technical report, Conseil National de Productivité.

Melitz, M. J. and Polanec, S. (2015). Dynamic olley-pakes productivity decomposition with entry and exit. The Rand journal of economics, 46(2):362-375.

Möller, J. (2010). The german labor market response in the world recession-de-mystifying a miracle. Zeitschrift für Arbeitsmarktforschung, 42(4):325.

Mueller, S. (2008). Capital stock approximation using firm level panel data: A modified perpetual inventory approach. Journal of Economics and Statistics (Jahrbuecher fuer Nationaloekonomie und Statistik), 228(4):357-371. 
NIESR, IVIE, and the University of Valencia (2016). Total factor productivity growth: Drivers, components and frontier firms. Technical Report 61064, WIFO Studies.

Olley, G. and Pakes, A. (1996). The dynamics of productivity in the telecommunications equipment industry. Econometrica, 64(6):1263-1297.

Peneder, M. (2003). Industrial structure and aggregate growth. Structural change and economic dynamics, 14(4):427-448.

Rodrik, D. (2016). Premature deindustrialization. Journal of economic growth, 21(1):1-33.

Schumpeter, J. A. (1942). Capitalism, socialism and democracy. New York: Harper.

Sheskin, D. J. (2003). Handbook of parametric and nonparametric statistical procedures. Chapman and Hall/CRC.

Syverson, C. (2011). What determines productivity? Journal of Economic literature, 49(2):326-65.

Wagner, J. (2007). Exports and productivity: A survey of the evidence from firm-level data. The World Economy, 30(1):60-82.

Wagner, J. (2010). Estimated capital stock values for german manufacturing enterprises covered by the cost structure surveys. Schmollers Jahrbuch, 130(3):403-408.

Yu, X., Dosi, G., Grazzi, M., and Lei, J. (2017). Inside the virtuous circle between productivity, profitability, investment and corporate growth: An anatomy of chinese industrialization. Research Policy, 46(5):1020-1038.

\section{Appendix A. Data Sources}

\section{A.1 German data and access terms}

The German AFiD (Amtliche Frimdaten fûr Deutschland) database of the German Statistical Office (Destatis) consists of 6 surveys over the period 2003-2013, each with a different coverage. Three of these provide information at the firm level and the remaining three are collected at the level of plant. Due to confidentiality constraints, a threshold of 20 or more employees applies for both firm and plant surveys. Below this threshold no data is observed. 
This means that a multi-plant firm owning only plants with less than 20 employees each appears in the plant-level surveys, while the firm (as a whole) does not appear in the firm-level surveys, if the sum of employees in all its plants is equal or greater to 20.

Among these surveys, our main source is the cost structure survey (CSS). The CSS is a one-step stratified random sample of German firms with at least 20 employees. It provides representative firm information on a yearly basis and covers about $40 \%$ of firms in the manufacturing sector. The focus is on the manufacturing sector because, despite figures for other sectors are available, the quality of German data on these is less reliable. The metadata can be retrieved from http://www.forschungsdatenzentrum.de/bestand/ kse_panel/kse_panel_metadatenreport_1995-2014.pdf

The number of employees in the CSS is measured in full time equivalents: number of owners working in the firm plus number of employees minus number of part-time employees plus full-time equivalents of part-time employees. Even if we observe data stating on 2001, we start our analysis in 2003 due to the change in measurement methodology in 2002 causing a break in the series of the number hours worked in Germany. Finally, capital stocks are not available from any of these surveys.

It is worth mentioning that despite the fact that the "annual report survey" is a firm-level census and covers around 95\% of firms above 20 employees, we can't rely on it as a main source because it lacks many variables needed for our productivity computations. Particularly, labor in full time equivalents, this being particularly relevant given that German labor market reforms made part-time contracts much more common in Germany ${ }^{11}$

The manufacturing industry is defined as category $\mathrm{C}$ of the first level of the Klassifikation der Wirtschaftszweige, Ausgabe 2008 (WZ 2008) and the 10-33 2-digits of the second level of the WZ, 2008. Both levels are common to the Statistical Classification of Economic Activities in the European Community (NACE) and the International Standard Industrial Classification of All Economic Activities (ISIC).

\footnotetext{
${ }^{11}$ "The fragile comparability of working time in France and Germany" by Thomas Körner (Destatis), Loup Wolff (Insee, CEE).
} 


\section{A.2 French data and access terms}

Our data sources for French firms come from the FICUS and FARE bases and are made available by the DGFiP- INSEE. These bases are drawn from fiscal files and no firm size threshold determining the inclusion/exclusion is applied. Hence, there is full coverage of French firms given that every firm is subject to compulsory reporting with fiscal authorities. The FICUS-FARE base contains balance sheet information on employment, capital, depreciation, investment, the wage bill, materials, four-digit sector the firm belongs to, etc. that are important in estimating productivity. In addition, a unique firm identifier is associated to each firm (siren number). Mergers and acquisitions and changes in intra-group organization can break the firm identifier series given that the siren changes over time. Therefore, new sirens do not necessary reflect to new firms in the market.

Given that, on the one hand the French bases provide full coverage of firms and contain all information needed for computing productivity measures, while on the other hand German data is subject to much more constraints, we don't use all French variables directly from the raw data (e.g. capital stocks and deflators), but instead we adapt the construction of French variables in order to harmonize measurement methodology. Particularly we keep only firms with 20 employees or more within the manufacturing sector.

The manufacturing industry is defined as category $\mathrm{C}$ of the first level of the Nomenclature d'Activité Française, rev 2 (NAF rev. 2, 2008) and the 10-33 2-digits of the second level of the NAF. Both levels are common to the Statistical Classification of Economic Activities in the European Community (NACE) and the International Standard Industrial Classification of All Economic Activities (ISIC). 
Table A1: Firm level variables correspondence

\begin{tabular}{|c|c|c|c|c|c|}
\hline & TRANSLATION & VAR CODE FR & VAR CODE DE & VAR NAME FR & VAR NAME DE \\
\hline \multicolumn{6}{|c|}{ Sales } \\
\hline+ & sales trading goods & VENTMAR & [kse_ef37] & Vente de marchandises & Umsatz: aus Handelsware \\
\hline+ & sales own products & \multirow{3}{*}{ PRODVEN } & [kse_ef35] & \multirow{3}{*}{ Production vendue de biens et services } & Umsatz: aus eigenen Erzeugnissen \\
\hline+ & commission fees from commercial mediation & & [kse_ef38] & & Umsatz: aus eigenen Erzeugnissen \\
\hline+ & other sales & & [kse_ef39] & & Umsatz: aus Handelsware \\
\hline$=$ & total sales & CATOTAL & [kse_ef40] & Chiffre d'affaires total & $\begin{array}{l}\text { Umsatz insgesamt (Summe aus kse_ef35 bis } \\
\text { kese_ef39) }\end{array}$ \\
\hline \multicolumn{6}{|c|}{ Stocks } \\
\hline - & stock intermediate/finished products at t0 & & [kse_ef41] & & $\begin{array}{l}\text { Bestände an unfertigen/ fertigen Erzeugnis- } \\
\text { sen aus eigener Produktion Anfangsbestand }\end{array}$ \\
\hline+ & stock intermediate/finished products at $\mathrm{t} 1$ & & [kse_ef42] & & $\begin{array}{l}\text { Bestände an unfertigen/ fertigen Erzeugnis- } \\
\text { sen aus eigener Produktion Endbestand }\end{array}$ \\
\hline$=$ & $\begin{array}{l}\text { change in inventories of intermedi- } \\
\text { ated/finished products }\end{array}$ & PRODSTO & & Production stockée & \\
\hline+ & self-produced capitalized assets & PRODIMM & [kse_ef44] & Production immobilisée & $\begin{array}{l}\text { Wert der im Geschäftsjahr aktivierten selb- } \\
\text { sterstellten Anlagen }\end{array}$ \\
\hline \multicolumn{6}{|c|}{ Raw materials } \\
\hline+ & stock raw material at t0 & & [kse_ef50] & & $\begin{array}{l}\text { Bestände an Roh- Hilfs- und Betriebsstoffen } \\
\text { zu Beginn des Geschäftsja }\end{array}$ \\
\hline- & stock raw material at $\mathrm{t} 1$ & & [kse_ef51] & & $\begin{array}{l}\text { Bestände an Roh- Hilfs- und Betriebsstoffen } \\
\text { am Ende des Geschäftsjahr }\end{array}$ \\
\hline$=$ & change in inventories raw material & VARSTMP & & $\begin{array}{l}\text { Variation de stocks de matières premières et } \\
\text { approvisionnements }\end{array}$ & Bestandsveränderung R/H/B-Stoffe \\
\hline- & purchases raw material & ACHAMPR & [kse_ef52] & $\begin{array}{l}\text { Achats de matières premières yc droits de } \\
\text { douane }\end{array}$ & $\begin{array}{l}\text { Eingänge (Einkäufe) von Roh- Hilfs- und Be- } \\
\text { triebsstoffen während des G }\end{array}$ \\
\hline \multicolumn{6}{|c|}{ Trading goods } \\
\hline+ & stock trading goods at t0 & & [kse_ef56] & & $\begin{array}{l}\text { Bestand an Handeslwaren zu Beginn des } \\
\text { Geschäftsjahres }\end{array}$ \\
\hline - & stock trading goods at $\mathrm{t} 1$ & & [kse_ef57] & & $\begin{array}{l}\text { Bestand an Handeslwaren am Ende des } \\
\text { Geschäftsjahres }\end{array}$ \\
\hline$=$ & change in inventories trading goods & VARSTMA & & Variation de stocks de marchandises & Bestandsveränderung Handelwaren \\
\hline- & purchases trading goods & ACHAMAR & [kse_ef58] & Achats de marchandises & $\begin{array}{l}\text { Eingänge (Einkäufe) an Handeslwaren } \\
\text { während des Geschäftsjahres }\end{array}$ \\
\hline \multicolumn{6}{|c|}{ Other cost } \\
\hline- & cost of hired workers & & [kse_ef63] & & Kosten für Leiharbeiter \\
\hline - & cost of wagework by other firms & AUTACHA & [kse_ef64] & Autres achats et charges externes & $\begin{array}{l}\text { Kosten für durch andere Unternehmen } \\
\text { durchgeführte Lohnarbeiten }\end{array}$ \\
\hline
\end{tabular}


Table A1 - Continued from previous page

\begin{tabular}{|c|c|c|c|c|c|}
\hline- & cost of repair work & & [kse_ef65] & & $\begin{array}{l}\text { Kosten für Reparaturen, Instandhaltungen, } \\
\text { Installation, Montagen u.ä }\end{array}$ \\
\hline- & rent, leasing & & [kse_ef66] & & Kosten für Mieten, Pachten und Leasing \\
\hline- & other cost & & [kse_ef68] & & sonstige Kosten \\
\hline & $=$ Value Added & VAHT & & Valeur ajoutée hors taxes & \\
\hline
\end{tabular}

\begin{tabular}{|c|c|c|c|c|c|}
\hline \multicolumn{6}{|c|}{ Employees } \\
\hline+ & Owners working in the firm & \multirow{4}{*}{ EFFSALM } & [kse_ef21] & \multirow{4}{*}{ Effectif salarié moyen (equiv. temps plein) } & Anzahl der tätigen Inhaber \\
\hline+ & Total employees & & [kse_ef22] & & Anzahl der Arbeitnehmer insgesamt \\
\hline - & Part-time employees & & [kse_ef24] & & $\begin{array}{l}\text { Anzahl der Arbeitnehmer: } \\
\text { Teilzeitbeschäftigte. }\end{array}$ \\
\hline+ & Full-time equivalents of part-time employees & & [kse_ef25] & & $\begin{array}{l}\text { Anzahl der Arbeitnehmer: darunter } \\
\text { Teilzeitbeschäftigte, umgerechnet in } \\
\text { Vollzeitäquivalente }\end{array}$ \\
\hline \multicolumn{6}{|c|}{ Wage bill } \\
\hline+ & Gross compensation & SALTRAI & [kse_ef60] & Salaires et traitements & $\begin{array}{l}\text { geleistete Bruttoentgelte (ohne Arbeitgeber- } \\
\text { anteile) }\end{array}$ \\
\hline+ & Social contribution by employer & CHARSOC & $\begin{array}{l}{[\text { kse_ef61] }} \\
{[\text { kse_ef62 }]}\end{array}$ & Charges sociales & $\begin{array}{lll}\text { geleistete } \quad \text { Bruttoentgelte }+ & \text { sonstige } \\
\text { Sozialkosten (Arbeitgeberanteile) } & \end{array}$ \\
\hline \multicolumn{6}{|c|}{ Depreciation } \\
\hline & Amount of depreciation & DOTAMOR & [kse_ef74] & $\begin{array}{l}\text { Immobilisations: dotations aux ammortisse- } \\
\text { ments }\end{array}$ & $\begin{array}{l}\text { Steuerliche Abschreibungen auf Sachanla- } \\
\text { gen }\end{array}$ \\
\hline \multicolumn{6}{|c|}{ Exports } \\
\hline & Total exports & CAEXPOR & [mb_26] & Chiffre d'affaires à l'export & Auslandsumsatz insgesamt in $€$ \\
\hline
\end{tabular}

Sources: FICUS-FARE from INSEE-DGFip for France (CASD) and CCS module of AFDiD from Destatis for Germany. 


\section{A.3 List of manufacturing sectors}

Table A2: Manufacturing 2-digits NACE Sectors

\begin{tabular}{|c|c|c|c|}
\hline NACE code & NACE names & OECD taxonomy & Inclusion \\
\hline 10 & Food products & MLT & YES \\
\hline 11 & Beverages & MLT & NO \\
\hline 12 & Tobacco products & MLT & NO \\
\hline 13 & Textiles & MLT & YES \\
\hline 14 & Wearing apparel & MLT & NO \\
\hline 15 & Leather and related products & MLT & NO \\
\hline 16 & $\begin{array}{l}\text { Wood and of products of wood and cork, except furniture; } \\
\text { articles of straw and plaiting materials }\end{array}$ & MLT & NO \\
\hline 17 & Paper and paper products & MLT & YES \\
\hline 18 & Printing and reproduction of recorded media & MLT & NO \\
\hline 19 & Coke and refined petroleum products & MLT & NO \\
\hline 20 & Chemicals and chemical products & MHT & YES \\
\hline 21 & $\begin{array}{l}\text { Basic pharmaceutical products and pharmaceutical } \\
\text { preparations }\end{array}$ & HT & NO \\
\hline 22 & Rubber and plastic products & MT & YES \\
\hline 23 & Other non-metallic mineral products & MT & YES \\
\hline 24 & Basic metals & MT & YES \\
\hline 25 & Fabricated metal products, except machinery and equipment & MLT & YES \\
\hline 26 & Computer, electronic and optical products & $\mathrm{HT}$ & YES \\
\hline 27 & Electrical equipment & MHT & YES \\
\hline 28 & Machinery and equipment n.e.c. & MHT & YES \\
\hline 29 & Motor vehicles, trailers and semi-trailers & MHT & YES \\
\hline 30 & Other transport equipment & MHT & NO \\
\hline 31 & Furniture & MLT & YES \\
\hline 32 & Other manufacturing & MT & YES \\
\hline 33 & Repair and installation of machinery and equipment & MT & YES \\
\hline
\end{tabular}




\section{Appendix B. Labor productivity growth decompositions}

We report below the decompositions of aggregate labour productivity growth across sectors (Table B1) and across firm of different sizes and export intensity (Table B2, The results from both decomposition exercises are very similar to the ones shown in Sections 6.2 and 6.3, and obtained by using total factor productivity (TFP). Overall, France scored a higher productivity growth than Germany in the post-recession phase, although the difference in growth rates is much smaller than what observed with TFP. France's growth advantage is also systematic across manufacturing sectors. Moreover, in both countries postrecession productivity dynamics was largely driven by the significant (positive or negative) growth of few sectors. Table B1) reveal the presence of a composition effect similar to the one highlighted in Section 6.2: within sectors efficiency gains contributed the most to productivity growth at the aggregate level whereas sectoral growth rates were mostly driven by market shares reallocation. Finally, Table B2 confirms the same results highlighted Section 6.3 with respect to the role of firm size and firm export intensity. In particular, medim-sized firms and firms with medium export intensity drove France's productivity catching-up in the post-recession phase. The sole noticeable difference concerns, the contribution of strong exporters. In Germany, this group of firms scored a robust positive growth in terms of value added per hour and it contributed to widen the productivity gap with French firms, while the opposite was observed using tfp as a productivity metric (compare Table B2 with Table 9 in Section 6.3). 
Table B1: Structural Change and Labour Productivity Growth

\begin{tabular}{llrrrr}
\hline ISIC & Sector Name & $\Delta \pi \times s$ & $\pi \times \Delta s$ & $\Delta \pi \times \Delta s$ & $\Delta$ tot \\
\hline & & \multicolumn{4}{c}{ France } \\
\cline { 2 - 5 } $10-33$ & All Manufacturing & 2.110 & -1.000 & 0.478 & 1.588 \\
10 & Food products & 0.150 & 1.172 & 0.035 & 1.357 \\
17 & Paper and paper products & 0.122 & -0.017 & 0.000 & 0.104 \\
20 & Chemicals and chemical products & 0.185 & 0.583 & 0.016 & 0.784 \\
22 & Rubber and plastic products & 0.371 & 0.645 & 0.034 & 1.050 \\
23 & Other non-metallic mineral products & 0.096 & 0.059 & 0.002 & 0.157 \\
24 & Basic metals & -0.016 & -1.145 & 0.020 & -1.141 \\
25 & Fabricated metal products & 0.177 & 0.682 & 0.034 & 0.894 \\
26 & Computer, electronic and optical products & 0.478 & 0.856 & 0.108 & 1.441 \\
27 & Electrical equipment & 0.339 & 0.908 & 0.108 & 1.355 \\
28 & Machinery and equipment n.e.c. & 0.199 & -1.393 & -0.021 & -1.214 \\
29 & Motor vehicles, trailers and semi-trailers & -0.128 & -3.906 & 0.130 & -3.904 \\
32 & Other manufacturing & 0.022 & 0.113 & 0.001 & 0.135 \\
33 & Repair and installation & 0.116 & 0.441 & 0.011 & 0.569 \\
& & & & \\
& & & Germany & \\
$10-33$ & All Manufacturing & 0.765 & 0.501 & 0.272 & 1.539 \\
10 & Food products & -0.090 & -0.390 & 0.020 & -0.459 \\
17 & Paper and paper products & 0.091 & 0.058 & 0.005 & 0.154 \\
20 & Chemicals and chemical products & 0.111 & 0.307 & 0.005 & 0.424 \\
22 & Rubber and plastic products & 0.044 & 0.018 & 0.000 & 0.062 \\
23 & Other non-metallic mineral products & 0.088 & -0.066 & -0.002 & 0.020 \\
24 & Basic metals & -0.067 & -0.840 & 0.015 & -0.893 \\
25 & Fabricated metal products & 0.016 & -0.034 & -0.001 & -0.020 \\
26 & Computer, electronic and optical products & 0.188 & 0.889 & 0.064 & 1.141 \\
27 & Electrical equipment & 0.340 & 1.581 & 0.103 & 2.024 \\
28 & Machinery and equipment n.e.c. & -0.242 & -1.664 & 0.036 & -1.870 \\
29 & Motor vehicles, trailers and semi-trailers & 0.236 & 0.684 & 0.013 & 0.933 \\
32 & Other manufacturing & 0.032 & -0.020 & 0.011 & 0.023 \\
33 & Repair and installation & 0.018 & -0.022 & 0.002 & -0.001 \\
\hline & & & & &
\end{tabular}

Values are in percentage. 
Table B2: Firm Size, Firm Export Intensity and Labour Productivity Growth

\begin{tabular}{lcccc}
\hline & $\Delta \pi \times s$ & $\pi \times \Delta s$ & $\Delta \pi \times \Delta s$ & $\Delta$ tot \\
\hline & All firms & & & \\
FR & 2.110 & -1.000 & 0.478 & 1.588 \\
DE & 0.765 & 0.501 & 0.272 & 1.539 \\
$\Delta$ FR-DE & 1.344 & -1.501 & 0.206 & 0.049 \\
\hline
\end{tabular}

Firm Size

\begin{tabular}{llcccc} 
FR & Small & 1.535 & -5.539 & -0.049 & -4.053 \\
& Medium & 0.396 & 1.430 & 0.271 & 2.096 \\
Large & 0.179 & 3.110 & 0.256 & 3.545 \\
& & & & & \\
SE & & -0.015 & -1.674 & 0.026 & -1.663 \\
& Medium & 0.325 & -4.612 & -0.017 & -4.304 \\
& Large & 0.455 & 6.787 & 0.263 & 7.506 \\
& & & & \\
$\Delta$ FR-DE & Small & 1.550 & -3.865 & -0.075 & -2.390 \\
& Medium & 0.071 & 6.042 & 0.287 & 6.400 \\
& Large & -0.276 & -3.678 & -0.007 & -3.961 \\
\hline
\end{tabular}

\section{Export Intensity}

\begin{tabular}{llcccc} 
FR & Weak & 0.362 & 0.588 & 0.018 & 0.967 \\
& Medium & 1.199 & -0.574 & 0.352 & 0.977 \\
& Strong & 0.549 & -1.014 & 0.108 & -0.357 \\
& & & & & \\
DE & Weak & 0.065 & 0.076 & 0.037 & 0.178 \\
& Medium & 0.642 & -5.257 & 0.004 & -4.610 \\
& Strong & 0.058 & 5.682 & 0.231 & 5.971 \\
& & & & & \\
\multirow{2}{*}{$\Delta$ FR-DE } & Weak & 0.297 & 0.512 & -0.019 & 0.789 \\
& Medium & 0.557 & 4.682 & 0.348 & 5.588 \\
& Strong & 0.491 & -6.695 & -0.123 & -6.328 \\
\hline
\end{tabular}

The aggregate productivity growth rate is computed as the relative change in labour productivity between the period 2009-2013 and the period 2003-2007 Classification by firm size. small: firms with less than 250 employees in full-time equivalents on average; medium: firms with more than 250 and less than 500 employees in full-time equivalents; large: firms with at least 500 employees. Classification by export intensity. weak: firms exporting less than $20 \%$ of their total output; medium: firms exporting between $20 \%$ and $50 \%$ of their total output; strong: firms exporting more than $50 \%$ of their total output 


\section{ABOUT OFCE}

The Paris-based Observatoire français des conjonctures économiques (OFCE), or French Economic Observatory is an independent and publicly-funded centre whose activities focus on economic research, forecasting and the evaluation of public policy.

Its 1981 founding charter established it as part of the French Fondation nationale des sciences politiques (Sciences Po), and gave it the mission is to "ensure that the fruits of scientific rigour and academic independence serve the public debate about the economy". The OFCE fulfils this mission by conducting theoretical and empirical studies, taking part in international scientific networks, and assuring a regular presence in the media through close cooperation with the French and European public authorities. The work of the OFCE covers most fields of economic analysis, from macroeconomics, growth, social welfare programmes, taxation and employment policy to sustainable development, competition, innovation and regulatory affairs.

\section{ABOUT SCIENCES PO}

Sciences $\mathrm{Po}$ is an institution of higher education and research in the humanities and social sciences. Its work in law, economics, history, political science and sociology is pursued through ten research units and several crosscutting programmes.

Its research community includes over two hundred twenty members and three hundred fifty PhD candidates. Recognized internationally, their work covers a wide range of topics including education, democracies, urban development, globalization and public health.

One of Sciences Po's key objectives is to make a significant contribution to methodological, epistemological and theoretical advances in the humanities and social sciences. Sciences Po's mission is also to share the results of its research with the international research community, students, and more broadly, society as a whole. 